\title{
Estudo da prematuridade em fetos com hérnia \\ diafragmática congênita: avaliação de fatores de predição
}

Dissertação apresentada à Faculdade de Medicina da Universidade de São Paulo para obtenção do título de Mestre em Ciências

Programa de Obstetrícia e Ginecologia

Orientadora: Dra. Lisandra Stein Bernardes Ciampi de Andrade

\section{São Paulo}


Dados Internacionais de Catalogação na Publicação (CIP)

Preparada pela Biblioteca da

Faculdade de Medicina da Universidade de São Paulo

(Creprodução autorizada pelo autor

Barbosa, Bruna Maria Lopes

Estudo da prematuridade em fetos com hérnia diafragmática congênita : avaliação de fatores de predição / Bruna Maria Lopes Barbosa. -- São Paulo, 2015.

Dissertação(mestrado)--Faculdade de Medicina da Universidade de São Paulo.

Programa de Obstetrícia e Ginecologia.

Orientadora: Lisandra Stein Bernardes Ciampi de Andrade.

Descritores: 1.Parto prematuro 2.Hérnia diafragmática 3.Anormalidades congênitas 4.Previsões 5.Medição de risco 6.Ultrassom

USP/FM/DBD-005/15 
Dedico este trabalho ao Senhor Deus, que sustenta e abençoa minha vida todos os dias.

Aos meus pais, João e Celeste, por todo amor, dedicação e exemplo de caráter e honestidade. Vocês fizeram tudo para que pudessem me oferecer as melhores oportunidades de crescer na vida. Eu não seria nada sem vocês. Meu amor e gratidão serão eternos.

Ao meu esposo Daniel, meu amor, companheiro e melhor amigo, por estar sempre ao meu lado, pelo apoio e toda compressão nas horas mais difíceis.

Aos meus queridos irmãos e cunhadas, Cassiano e Marlice, Marco Aurélio e Maíra, pelos finais de semanas divertidos em família.

Aos pequenos e adoráveis Gustavo, Caio, Lucas e Pedro. Vocês chegaram para tornar minha vida mais doce e colorida.

Ao meu pequeno grande amor, tão aguardado, Eduardo. 


\section{AGRADECIMENTOS}

Ao Prof. Dr. Marcelo Zugaib, digníssimo Professor Titular da Disciplina de Obstetrícia do Departamento de Obstetrícia e Ginecologia da Faculdade de Medicina da Universidade de São Paulo, pela recepção, atenção, acolhimento e oportunidade de realizar este estudo.

À Dra. Lisandra Stein Bernardes, minha orientadora, por todos os ensinamentos, pelo tempo disponibilizado, pela atenção, paciência e incentivo, que foram fundamentais para realização deste trabalho e também, para minha formação profissional. Obrigada também por seu trabalho junto à análise estatística.

À Prof. Dra. Rossana Pucineli Vieira Francisco, pela receptividade, atenção e exemplo. Agradeço também por sua presença em minha banca de qualificação e por todas as críticas e sugestões dadas para o aprimoramento deste estudo.

Ao Prof. Dr. Roberto Eduardo Bittar, pela idéia e participação no projeto deste estudo.

Ao Prof. Dr. Victor Bunduki, por todos os ensinamentos, momentos de descontração e por sua presença em minha qualificação, que muito contribuíram a melhorar esse trabalho.

À Prof. Dra. Ana Cristina Tannuri, por sua presença em minha banca de qualificação e por todas as sugestões dadas, que também foram muito importantes para melhorar este trabalho.

Aos assistentes da Medicina Fetal, Prof. Dr. Marco Antônio Borges, Prof. Dr. Antonio Amorim, Prof. Dr. Adolfo Liao, Prof. Dr. Mário Henrinque Burlacchini de Carvalho, Prof. Dra. Maria de Lourdes Brizot e Dra. Joelma Queiroz Andrade, por 
todos os ensinamentos e atenção nos ambulatórios de Medicina Fetal, que muito contribuíram para minha formação profissional.

Às minhas grandes amigas, Karen Hettfleisch e Mariana Azevedo, colegas de pós graduação que se tornaram verdadeiras amigas, com quem compartilhei momentos únicos, de alegrias e dificuldades, vida pessoal e profissional e que também muito me apoiaram na realização deste trabalho. Obrigada por tudo, jamais me esquecerei de vocês.

Às queridas Carolina Fiori, Carolina Vilas Boas, Janaina Damázio Negrão, Julianny Cavalheiro Nery, Mariana Miyadahira, Marisa Takeno e Rimena Melo, por todos os momentos divididos, desde o aprendizado aos momentos de descontração e risadas.

A todos colegas pós-graduandos, estagiários e residentes, com os quais convivi no HC, pelo companheirismo e pelo bom relacionamento profissional vivenciado.

A todos os assistentes da Clínica Obstétrica do HCFMUSP, que contribuíram de forma direta ou indireta para realização desse estudo.

À ex-secretária da pós-graduação Adriana e à secretária atual Lucinda por toda atenção e ajuda competente nos atos burocráticos.

À Ágatha pela preciosa e competente ajuda na análise estatística.

Aos funcionários Alan, Willian, Guilherme, Raquel, Soraia e Célia pela atenção e colaboração necessária para a realização deste trabalho.

À equipe de enfermagem da Clínica Obstétrica do HCFMUSP, pela colaboração e disponibilidade.

Às pacientes, com as quais aprendo mais a cada dia. Sem vocês este estudo jamais seria possível. 
Esta dissertação está de acordo com as seguintes normas, em vigor no momento desta publicação:

Referências: adaptado de International Committee of Medical Journals Editors (Vancouver).

Universidade de São Paulo. Faculdade de Medicina. Divisão de Biblioteca e Documentação. Guia de apresentação de dissertações, teses e monografias. Elaborado por Anneliese Carneiro da Cunha, Maria Julia de A. L. Freddi, Maria F. Crestana, Marinalva de Souza Aragão, Suely Campos Cardoso, Valéria Vilhena. $3^{\text {a }}$ ed. São Paulo: Divisão de Biblioteca e Documentação; 2011.

Abreviaturas dos títulos dos periódicos de acordo com List of Journals Indexed in Index Medicus 


\section{Sumário}

Lista de siglas, símbolos e abreviações

Lista de figuras

Lista de tabelas

Resumo

Summary

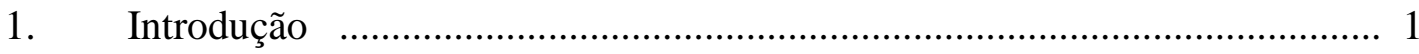

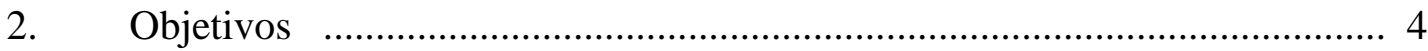

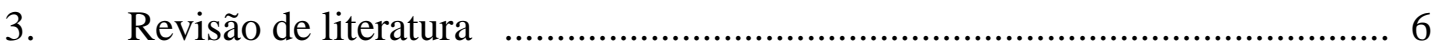

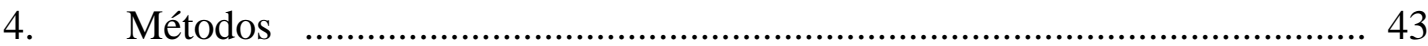

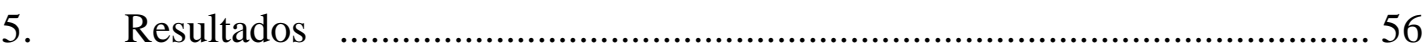

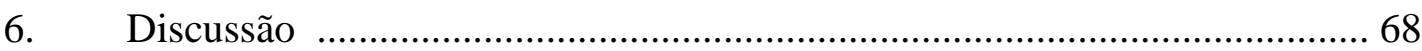

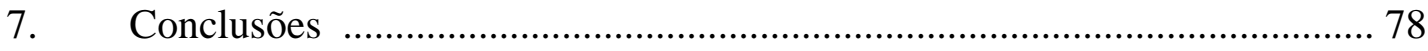

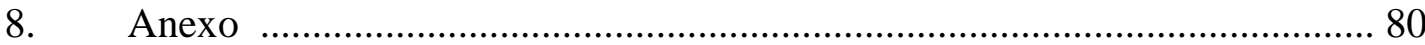

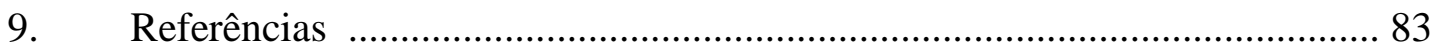




\section{LISTA DE SIGLAS, SÍMBOLOS E ABREVIATURAS}

BPD - Diâmetro biparietal

CA - Circunferência abdominal

CAPPesp - Comissão de Ética para Análise de Projetos de Pesquisa

CC - Circunferência cefálica

CIV - Comunicação interventricular

cm - Centímetros

ECMO - Oxigenação por membrana extracorpórea

et al. - e outros ( mesmo que "e colaboradores")

F - Fêmur

FMUSP - Faculdade de Medicina da Universidade de São Paulo

GIG - Grande para a idade gestacional

HAP - Hipertensão arterial pulmonar

HC-FMUSP - Hospital das Clínicas da Faculdade de Medicina da Universidade de São

Paulo

HDC - Hérnia diafragmática congênita

IC - Intervalo de confiança

ILA - Índice de Líquido Amniótico

LiTR - Proporção entre entre o volume do fígado herniado na cavidade torácica e o volume total da cavidade torácica

LHR - lung head ratio

LHRo/e - LHR observado/esperado

MB - Maior bolsão vertical 
mg - Miligramas

mm - Milímetros

n - Número

$\mathrm{OR}$ - odds ratio

P - Percentil

P10 - percentil 10

RNM - Ressonância nuclear magnética

ROC - receiver operator characteristic (curva de características operacionais)

RPMO - Rotura prematura de membranas ovulares

$\mathrm{RR}$ - Risco relativo

SINASC - Sistema de Informações sobre Nascidos Vivos

TPP - Trabalho de parto prematuro

vs - versus

$1^{\circ}$ - Primeiro

$5^{\circ}$ - Quinto

$8^{\mathrm{a}}$ - Oitava

$11^{\mathrm{a}}$ - Décima primeira

$12^{\mathrm{a}}$ - Décima segunda

$32^{\mathrm{a}}$ - Trigésima segunda

$38^{a}$ - Trigésima oitava

$39^{a}$ - Trigésima nona

$\%$ - Porcento

= - Igual

$\geq-$ Maior ou igual a

$\leq-$ Menor ou igual a 
$>$ - Maior que

$<-$ Menor que

* - operação de multiplicação 


\section{LISTA DE FIGURAS}

Figura 1 Técnica dos quatro quadrantes para medida do ILA, descrita por Phelan et al.

Figura 2 Medida do maior bolsão vertical 47

Figura 3 Corte do tórax a nível de 4 câmaras, em feto portador de hérnia diafragmática esquerda 50

Figura 4 Medida da área pelo método maior diâmetro, do pulmão contralateral à hérnia 51

Figura 5 Fluxograma com a caracterização da população estudada 53

Figura 6 Curva ROC do LHRo/e para predição de prematuridade 66 


\section{LISTA DE TABELAS}

Tabela 1

Tabela 2

Tabela 3

Tabela 5

Tabela 7
Fatores de risco para prematuridade espontânea (adaptado de Goffinet, $2005^{1}$ ) 22

Estudos que avaliaram a relação entre polidrâmnio e prematuridade 28 Estudos que avaliaram a taxa de prematuridade e sobrevida em fetos portadores de hérnia diafragmática congênita 39 Risco de parto prematuro por número de malformações congênitas e hérnia diafragmática congênita ( adaptado de Purisch et al., 2008) 41

Fórmula para calcular LHR esperado em fetos com hérnia diafragmática congênita esquerda e direita, usando o método do maior diâmetro, baseado na idade gestacional (IG) em semanas com decimais 50

Relação entre diferentes variáveis e prematuridade em 80 fetos com HDC, HC-FMUSP- Janeiro de 2001 a outubro de 2014..64 Resultado do modelo final de probabilidade estimada para prematuridade em fetos com HDC, HC-FMUSP- Janeiro de 2001 a outubro de 2014 65

Sensibilidade e especificidade do LHRo/e para predição da prematuridade em fetos com HDC, HC-FMUSP- Janeiro de 2001 a outubro de 2014 67 


\section{Resumo}

Barbosa BML. Estudo da prematuridade em fetos com hérnia diafragmática congênita: avaliação dos fatores de predição [dissertação]. São Paulo: Universidade de São Paulo, Faculdade de Medicina; 2015.

INTRODUÇÃO: A hérnia diafragmática congênita é uma malformação fetal potencialmente grave, que está associada a alta mortalidade. Sabe-se que a prematuridade é um significante fator de risco para morbidade e mortalidade neonatal na maioria das doenças, porém sua relação com a hérnia diafragmática congênita pouco tem sido descrita. $\mathrm{O}$ que se tem observado nos estudos nesses fetos é que a incidência de prematuridade é maior que na população em geral OBJETIVOS: Avaliar a incidência de prematuridade nos fetos com hérnia diafragmática congênita e seus possíveis fatores de predição. MÉTODOS: Estudo do tipo coorte retrospectiva. Foram avaliados fetos com hérnia diafragmática congênita, não submetidos a fetoscopia, sem alteração de cariótipo, com até uma malformação maior associada à hérnia, que fizeram o acompanhamento ultrassonográfico na Clínica Obstétrica do Hospital das Clínicas da Faculdade de Medicina da Universidade de São Paulo, no período entre janeiro de 2001 e outubro de 2014. As variáveis analisadas foram: idade materna, primiparidade, doenças maternas associadas, tabagismo, prematuridade anterior espontânea, malformação fetal associada à hérnia, hidropsia fetal, polidrâmnio na gestação, polidrâmnio no último ultrassom antes do parto, restriçã de crescimento fetal, feto grande para a idade gestacional, presença de fígado intratorácico, realização de procedimentos invasivos, lado da hérnia e LHRo/e. Inicialmente, para avaliar a associação com a prematuridade, as variáveis qualitativas foram submetidas ao teste de Qui-quadrado e as quantitativas ao teste não paramétrico de Mann-Whitney. Em seguida, foi ajustado um modelo de regressão logística múltipla com método de seleção de variáveis stewise para verificar quais variáveis poderiam influenciar na predição de prematuridade. Construiu-se curva(s) ROC para encontrar ponto de corte para a(s) variável(is) significativa(s) na predição de prematuridade, identificando-se os valores com melhor sensibilidade e especificidade a serem sugeridos para uso na prática clínica. RESULTADOS: Dos 80 fetos avaliados, 21 $(26,25 \%)$ nasceram prematuros. Após análise multivariada o LHRo/e foi o único fator associado à prematuridade $(p=0,02)$. A curva ROC mostrou que com o aumento do LHRo/e ocorre o aumento da sensibilidade e diminuição da especificidade na predição do parto prematuro, atingindo-se uma sensibilidade de 93,3\% com especificidade de $48,8 \%$ quando o LHRo/e é igual a $40 \%$. As demais variáveis não se associaram à prematuridade após análise múltipla. CONCLUSÕES: A incidência de prematuridade encontrada foi de $26,25 \%$. O LHRo/e foi o único fator preditor de prematuridade na amostra estudada.

Descritores: Parto prematuro; Hérnia diafragmática; Anormalidades congênitas; Previsões; Medição de risco; Ultrassom. 


\begin{abstract}
Barbosa BML. Study on prematurity in fetuses with congenital diaphragmatic hernia $(C D H)$ : evaluation of predictive factors [Dissertation]. São Paulo: "Faculdade de Medicina, Universidade de São Paulo"; 2015.
\end{abstract}

INTRODUCTION: Congenital diaphragmatic hernia $(\mathrm{CDH})$ is a severe fetal malformation that leads to high mortality. Premature birth significantly increase the risk of neonatal morbidity and mortality in most diseases; but its relationship with congenital diaphragmatic hernia has not been well described. Fetuses with diaphragmatic hernia have a higher incidence of prematurity when compared to fetuses without malformations. Furthermore, prematurity is associated with worse post-natal survival in these fetuses. However, no studies have evaluated possible prenatal predictive factors. OBJECTIVES: To evaluate the incidence of prematurity in fetuses with congenital diaphragmatic hernia $(\mathrm{CDH})$ and its possible predictive factors. METHODS: A retrospective cohort study was performed. Inclusion criteria were presence of congenital diaphragmatic hernia; absence of fetoscopy; absence of karyotype abnormality; maximum of one major malformation associated with diaphragmatic hernia; ultrasound monitoring at the Obstetrics Clinical of Clinicas Hospital at the University of São Paulo School of Medicine, from January 2001 to October 2014. The following variables were analyzed: maternal age, primiparity, associated maternal diseases, smoking, previous spontaneous preterm birth, fetal malformation associated with hernia, fetal hydrops, polyhydramnios during pregnancy, polyhydramnios on last ultrasound, fetal growth restriction, fetus large for gestational age, presence of intrathoracic liver, invasive procedures performed, side of hernia and observed to expected lung to head ratio (o/e LHR). On individual analysis, qualitative variables were assessed using the Chi-square test, and quantitative variables by the nonparametric test of Mann-Whitney. After individual analysis, a multiple logistic regression model with stewise variable selection method was performed to select variables variables that could influence the prediction of preterm delivery. A ROC curve was constructed with the significant variable, identifying the values with best sensitivity and specificity to be suggested for use in clinical practice.

RESULTS: Eighty fetuses were evaluated, of which 21 (26.25\%) were premature. After multiple analysis the o/e LHR was the only factor associated with prematurity $(p=$ $0,02)$. The ROC curve showed that as the o/e LHR increases the sensitivity also increases and there is a decrease in the specificity of preterm delivery prediction, reaching a sensitivity rate of $93.3 \%$ and a specificity of $48.8 \%$ when o/e LHR is equal to $40 \%$. The other variables were not associated with prematurity after multiple analysis. CONCLUSION: The incidence of prematurity was $26.25 \%$ in our population. The o/e LHR was the only predictor of prematurity in this sample.

Descriptors: Obstetric labor, premature; Hernia diaphragmatic; Congenital Abnormalities; Forecasting; Risk assessment; Ultrasonics. 
1 - INTRODUÇÃO 


\section{Introdução}

A hérnia diafragmática congênita (HDC) é uma malformação fetal potencialmente grave, com incidência de 1:2200 nascimentos ${ }^{2}$. Consiste num defeito anatômico, uma abertura no diafragma que pode levar a consequências devastadoras. A herniação das vísceras abdominais para o tórax resulta na compressão pulmonar e consequentemente hipoplasia e hipertensão pulmonar. Está associada à alta mortalidade, em torno de 50$60 \%{ }^{3}$.

O diagnóstico pré- natal é importante, pois permite o acompanhamento dos fetos, a orientação das pacientes, a intervenção pré-natal em alguns casos e a realização do parto em centro terciário, com equipes de neonatologia e cirurgia infantil preparadas para o recebimento e cuidados desses neonatos ${ }^{4,5}$.

Sabe-se que a prematuridade é um significante fator de risco para morbidade e mortalidade neonatal na maioria das doenças, responsável direta ou indiretamente por $75-88 \%$ da mortalidade perinatal em recém-nascidos. ${ }^{6}$ Sua relação com a HDC, no entanto, pouco tem sido descrita. O que se tem observado é que a incidência de prematuridade nesses fetos é maior que na população em geral e que, a sobrevida nesses recém-nascidos é menor nos prematuros do que nos nascidos a termo.

Em estudo realizado por Tsao et $a l^{7}$, em 2010, observou-se uma taxa de prematuridade de $22,4 \%$ e os recém-nascidos prematuros apresentaram sobrevida estatisticamente menor que os nascidos a termo.

Levison et al. ${ }^{8}$, em 2006, em estudo sobre incidência e sobrevivência de recémnascidos com HDC, observaram uma taxa de prematuridade de 30\%, também com a 
sobrevivência estatisticamente menor nos prematuros (30\% vs 64\%, OR 3.06, IC 95\%, 1.57-5.94). Neste estudo a prematuridade foi considerada um fator de risco independente para a mortalidade.

Purisch et al. ${ }^{9}$, em 2008, estudando as malformações fetais e sua relação com a prematuridade, encontraram uma taxa de prematuridade nos fetos com HDC de 23,1\% e, em relação ao risco de parto prematuro, quando comparado aos fetos sem malformação, um risco aumentado com OR de 3,2, IC 95\% 2,4-4,3.

Para Hedrick ${ }^{10}$, 2013, apesar da maioria dos fetos com HDC evoluírem para o termo, um subconjunto desses fetos, com hérnia grave, irá desenvolver polidrâmnio, aumentando o risco de parto prematuro. Acredita-se que a combinação da prematuridade com imaturidade pulmonar e hipoplasia pulmonar severa é frequentemente letal.

Não há até o momento nenhum estudo cujo objetivo tenha sido estudar os possíveis fatores associados à prematuridade em fetos com hérnia diafragmática congênita. Sabendo-se da importância da prematuridade na mortalidade e morbidade neonatal desses fetos e que a taxa de prematuridade nos fetos com HDC é maior que na população em geral, os objetivos deste trabalho são avaliar a incidência da prematuridade em fetos com HDC acompanhados no nosso serviço e estudar a prematuridade e seus possíveis fatores de risco especificamente para essa população. 


\section{2 - OBJETIVOS}




\section{Objetivos}

Avaliar :

1. Incidência de prematuridade em gestações de fetos com Hérnia Diafragmática Congênita;

2. Fatores que possam estar relacionados à predição de prematuridade nessa população. 
3 - REVISÃO DE LITERATURA 


\section{Revisão de literatura}

\subsection{Prematuridade na gestação}

A cada ano é estimado que 13 milhões de crianças nasçam antes de 37 semanas de gestação, sendo que as complicações decorrentes da prematuridade são consideradas a maior causa de mortalidade neonatal ${ }^{11} \mathrm{e}$ a segunda maior causa de morte em crianças abaixo de 5 anos, perdendo apenas para a pneumonia ${ }^{12}$.

Segundo Wen et al. ${ }^{13}$, em 2004, a taxa de parto prematuro foi calculada em $11 \%$ nos Estados Unidos, entre 5\% e 7\% na Europa e cerca de 6,5\% no Canadá. Nos países industrializados o nascimento prematuro é responsável por $70 \%$ da mortalidade neonatal e $75 \%$ de morbidade neonatal, contribuindo para problemas de desenvolvimento neurológico a longo prazo, disfunção pulmonar e problemas visuais. Além disso, a necessidade de cuidados intensivos para esses bebês acrescenta gastos importantes para o sistema de saúde. O custo anual estimado para a sociedade é de 26 bilhões de dólares. ${ }^{14}$

Em trabalho publicado por Saigal et al. ${ }^{15}$, em 2008, os nascidos prematuros quando comparados aos nascidos a termo, apresentaram maiores taxas de instabilidade de temperatura, dificuldade respiratória, infecções, apnéia, hipoglicemia, convulsões, icterícia, kernicterus, dificuldade de alimentação, enterocolite necrotizante, leucomalácia periventricular e reinternações hospitalares.

McIntire et al. ${ }^{16}$, também em 2008, publicaram estudo realizado no Parkland Hospital, em Dallas, nos Estados Unidos, incluindo todos os recém-nascidos únicos e sem anomalias, entre janeiro de 1988 e dezembro de 2005, de mães que realizaram o 
pré-natal na mesma instituição, totalizando 240958 casos. Os desfechos neonatais para nascimento prematuro tardio foram comparados com os de crianças nascidas na $39^{\text {a }}$ semana. Concluíram que as taxas de mortalidade para prematuros tardios ( 34, 35 e 36 semanas) foram significativamente maiores que os nascidos na $39^{a}$ semana. Ainda, a morbidade neonatal foi significativamente aumentada com 34, 35 e 36 semanas, incluindo a angústia respiratória tratada com ventilação mecânica, taquipnéia transitória, hemorragia intraventricular graus 1 e 2 , sepse diagnosticada pelo neonatologista, sepse comprovada por cultura, fototerapia por hiperbilirrubinemia e intubação na sala de parto.

Aproximadamente $30-35 \%$ dos partos prematuros são realizados por indicação materna ou fetal, $40-45 \%$ decorrentes de trabalho de prato prematuro e $25-30 \%$ precedidos por rotura prematura de membranas ovulares pretermo. Essas duas últimas são chamadas de partos prematuros espontâneos. ${ }^{17}$

\subsubsection{Fatores de risco para prematuridade espontânea}

Muitas características maternas e fetais têm sido relacionadas à prematuridade, entre elas: características demográficas maternas, história nutricional, história obstétrica, características da gestação atual, características psicológicas, infecções, contrações uterinas e comprimento cervical, e marcadores genéticos e biológicos. ${ }^{17}$ 


\subsubsection{Fatores individuais, socioeconômicos, psicológicos e comportamentais}

Nos Estados Unidos e no Reino Unido as mulheres negras apresentam consistentemente um risco maior para parto prematuro. As taxas de parto prematuro são em torno de $16-18 \%$ nas mulheres negras comparados com 5-9\% nas mulheres brancas. ${ }^{17}$ Cooper et al. ${ }^{18}$, em 1996, publicaram estudo realizado entre outubro de 1992 e julho de 1994, no Maternal-Fetal Institute of Child Health and Human Development. Avaliaram 2593 gestantes ( negras e não negras) e a raça negra foi associada ao parto prematuro espontâneo ( $<35$ semanas). O OR ajustado calculado foi 1,65, IC 95\% 1,01 $2,69, p=0,05$.

Goldenberg et al. ${ }^{19}$, em 1998, publicaram estudo multicêntrico, chamado "The Preterm Prediction Study",realizado em 10 centros do Maternal-Fetal Institute of Child Health and Human Development, entre outubro de 1992 e julho de 1994, em que avaliaram possíveis fatores de risco associados à prematuridade espontânea, entre eles, a raça negra. De 2929 gestantes avaliadas, 63\% eram negras e 37\% não negras. O risco relativo (RR) para parto prematuro ( $<37$ semanas nas negras foi de 1,5, IC 95\%, 1,21,9). Muitos estudos mostram que, mesmo após correção de outros fatores de risco conhecidos, as negras apresentam um risco de parto pretermo duas vezes maior que as brancas. ${ }^{19-21}$

A primiparidade também já foi relatada como maior risco para prematuridade espontânea, em relação às pacientes com parto anterior não prematuro. Ananth et al. ${ }^{22}$, em 2007, publicaram estudo analisando 414241 mulheres com gestações únicas, no período de 1989 a 1997, em Missouri. Compararam a idade gestacional do parto em 3 grupos: primíparas $(\mathrm{n}=259431)$, gestantes com um parto anterior a termo $(\mathrm{n}=139518)$, gestantes com um parto anterior prematuro $(n=15292)$. A taxa de prematuridade das 
primíparas $(9,6 \%)$ foi maior que nas pacientes com parto anterior a termo $(23,3 \%)$ e menor que nas pacientes com antecedente de prematuridade $(8,1 \%)$. Em comparação com as pacientes com parto anterior a termo, o risco para prematuridade espontânea nas primíparas e nas gestantes com prematuro anterior também foi maior, com RR (IC 95\%) de $1,13(1,10-1,16)$ e $2,5(2,40-2,60)$, respectivamente.

Outro estudo publicado por Meis et $a l .^{23}$, em 1995, mostrou associação entre nulíparas e parto prematuro. No entanto, o mesmo estudo observou também associação entre multíparas ( $\geq 3$ partos anteriores) e prematuridade ( parto prematuro $<257$ dias de gestação). Foram avaliadas através de análise de banco de dados em Cardiff, Wales, 25844 mulheres cujos partos aconteceram entre 1970 e 1979 . Os OR ajustados nas nulíparas e multíparas ( $\geq 3$ partos anteriores) foram respectivamente 1,29 ( IC 95\%, 1,08-1,55) e 1,32 (IC 95\%, 1,05-1,66). Nas pacientes com um ou 2 partos anteriores, o resultado foi não significativo.

Os extremos de idade materna e baixo nível socioeconômico também são considerados como fatores de risco para prematuridade. ${ }^{17}$ Goffinet ${ }^{1}$, revisando preditores primários de parto prematuro espontâneo, em 2005, destacou idade materna inferior a 15-19 anos e baixo nível socioeconômico. Outros fatores citados são: violência doméstica, estresse, depressão, pré-natal inadequado e baixo peso antes da gestação.

Em estudo publicado por Meis et $a l^{23}$.,em1995, concluiu-se que idade materna inferior a 18 anos e baixo nível social foram fatores de risco independente para prematuridade. Foram avaliadas 25844 gestações, das quais 4,3\% evoluíram com parto prematuro ( idade gestacional definida como menor de 257 dias . Os OR ajustados, para 
idade materna inferior a 18 anos e baixo nível socioeconômico foram 1,79, IC 95\% 1,31-2,46 e 1,44, IC 95\% 0,88-1,75 respectivamente.

Cooper et al. ${ }^{18}$ encontraram associação entre estresse e parto prematuro. O estudo foi realizado entre outubro de 1992 e julho de 1994, no "Maternal-Fetal Institute of Child Health and Human Development", incluindo 2593 gestantes. Foi considerado prematuro o parto espontâneo abaixo de 35 semanas. Cinco escalas foram adaptadas para mensurar ansiedade, autoestima, domínio, depressão e estresse e aplicadas entre 25 e 29 semanas de gestação. A análise revelou associação entre estresse e parto prematuro $(p=0,003)$

Berkowitz et $a .^{24}$, em 1983, publicaram estudo realizado em Connecticut, no período de janeiro de 1977 a janeiro de 1978, avaliando fatores psicossociais e parto prematuro espontâneo ( $<37$ semanas). Os grupos caso (prematuro) e controle (termo) tinham respectivamente 166 e 299 mulheres. Foi utilizado um questionário composto por 27 eventos do dia a dia ( score eventos da vida) para mensurar o nível de estresse psicológico durante a gravidez. Um outro score foi criado para mensurar o quanto a gravidez foi desejada ou não ( score de gravidez desejável). Os achados indicaram associação entre alto nível no score eventos da vida e parto pretermo nas mulheres brancas $(p<0,01)$. Porém, nas negras não houve essa associação $(p=0,59)$. Quando o score eventos da vida foram avaliados em conjunto com o score de gravidez desejável, tanto as mulheres brancas como as negras que apresentaram alta pontuação no score de gravidez desejável, foram consideradas de risco para parto prematuro quando expostas a alto nível comparadas a baixo nível de eventos da vida.

Outros estudos também têm relatado associação entre parto prematuro e estresse, ansiedade e depressão. ${ }^{25}$ 
Um fator comportamental importante de associação com a prematuridade é o tabagismo. Nos Estados Unidos $20-25 \%$ das mulheres grávidas fumam e destas, 12$15 \%$ continuam durante a gestação. ${ }^{26} \mathrm{O}$ mecanismo do tabagismo predispor a prematuridade parece incerto, mas há mais de 3000 substâncias no cigarro e os efeitos biológicos da maioria delas são desconhecidos. No entanto, a nicotina e o monóxido de carbono são poderosos vasoconstritores e estão associados a danos placentários e redução da circulação uteroplacentárea. ${ }^{17}$

Em metanálise realizada por Castles et al. $^{27}$, em 1999, constataram que o tabagismo está associado à prematuridade por estar fortemente associado com risco elevado de placenta prévia, descolamento prematuro de placenta e rotura prematura de membranas pretermo (RPMO) espontânea. A avaliação da RPMO nessa metanálise obteve um OR de 1,81, IC 95\% 1,36 - 2,25, comparando gestantes fumantes com não fumantes. Meis et al ${ }^{23}$, em 1995, demonstraram aumento da prematuridade progressivo de acordo com o número de cigarros fumados por dia, chegando a um OR ajustado de 1,39, IC 95\% 1,15-170, quando a mãe fumava 20 ou mais cigarros ao dia, comparadas às não fumantes.

O consumo de álcool parece não influenciar no risco de parto prematuro, exceto nos casos de consumo muito elevado. ${ }^{1}$

\subsubsection{História obstétrica e ginecológica}

A história de parto prematuro anterior ou perdas no secundo trimestre é considerada o principal fator de risco para prematuridade depois de ajustado os fatores de confusão. ${ }^{19,20,28}$ 
Iams et al. ${ }^{29}$, em 1998, observaram que em 378 pacientes com parto prematuro espontâneo anterior ou aborto espontâneo de segundo trimestre (gestações entre 18-36 semanas), a taxa de recorrência de parto prematuro espontâneo ( $<35$ semanas) variou entre 14 e 15\%, comparado com apenas 3\% em 904 mulheres com parto a termo anterior sem complicações.

McManemy et $a l^{30}$., em 2007, estudaram o risco de recorrência para parto prematuro, em estudo de coorte, em mulheres que tiveram 3 gestações únicas consecutivas com 19025 nascidos vivos entre 1989-1997. O estudo mostrou forte associação entre parto prematuro anterior e risco de recorrência, o qual foi influenciado pela frequência, ordem e precocidade da prematuridade anterior. A recorrência foi maior (57\%) para mulheres com 2 partos prematuros prévios entre 21-31 semanas e menor (33\%) para aquelas com 2 partos prematuros prévios entre 32-36 semanas. O risco de recorrência variou, sendo de $42 \%$ para mulheres com história de 2 partos prematuros anteriores, $21 \%$ para aquelas com o $1^{\circ}$ parto a termo e o $2^{\circ}$ pretermo, $13 \%$ para aquelas com o $1^{\mathrm{o}}$ parto pretermo e o $2^{\circ}$ parto a termo e $5 \%$ para as mulheres com 2 partos a termo.

Esplin et al. ${ }^{31}$, em 2008, também encontraram associação entre parto prematuro anterior e prematuridade. Foram incluídas em seu estudo 98724 mulheres, sendo que todas tiveram um primeiro parto com nascidos vivos e, pelo menos, um outro parto subsequente em Utah durante 1989-2001. Observaram que as mulheres que tiveram parto prematuro espontâneo abaixo de 34 semanas em seu primeiro ou segundo filho apresentaram a maior taxa de recorrência ( RR 13,56, IC 95\% 11,5-16). A história de parto prematuro espontâneo abaixo de 34 semanas foi considerada um forte preditor de parto pretermo subsequente. 
Carvalho et $a l^{32}$, em 2005, publicaram estudo realizado em nosso serviço, de janeiro de 1998 a junho de 2001. Avaliaram se a medida do colo realizada por ultrassom transvaginal e a presença de funil associados a antecedente de parto prematuro espontâneo seriam capaz de predizer parto prematuro abaixo de 34 semanas. Através da análise de regressão logística multivariada observaram que o comprimento cervical ( OR 1,12, IC 95\% 1,08-1,16, $p<0,001$ ), a presença de funil ( OR 6,29, IC 95\% 2,52$15,7, p<0,001$ ) e a história de prematuridade anterior ( OR 2,71, IC 95\% 1,44-5,09, $p<$ $0,02)$ foram significativamente associadas com parto pretermo abaixo de 34 semanas. A média da medida do comprimento do colo no grupo com antecedente de prematuridade foi significativamente menor que no grupo sem parto prematuro anterior ( $30,1 \mathrm{~mm} v \mathrm{~s}$ $35,8 \mathrm{~mm}, \mathrm{n}=180, p<0,001)$.

Rolnik et al., em 2013, em nosso serviço, estudaram 101 grávidas com feto único, sem malformações, com antecedente de parto prematuro espontâneo, sem sinais de trabalho de parto até 24 semanas e início de pré-natal até 20 semanas. Avaliaram a validade da medida do comprimento do colo para predição de parto prematuro. A medida do comprimento cervical esteve relacionado à ocorrência de parto prematuro, sendo capaz de predizer a prematuridade com 24, 27, 30 e 33 semanas, sendo os valores de corte para predição respectivamente iguais a 22, 21, 20 e 16 mm.

A história familiar (fatores genéticos) também tem sido relatada como fator de risco para prematuridade. ${ }^{18}$ Bhattacharya et al. ${ }^{14}$, em 2010 , em estudo realizado com 22343 gestantes, na Aberdeen Maternity Neonatal, observaram que o risco de uma mulher que nasceu de parto prematuro espontâneo ter um filho prematuro está significativamente aumentado (OR 1,60, IC 95\% 1,16-2,21). Observaram também que o risco de uma mulher ter um parto prematuro espontâneo está aumentado se a mãe dela 
tiver história de parto prematuro espontâneo em qualquer outra gestação (OR de 1,35, IC $95 \% 1,12-1,63)$.

História de cirurgias em colo uterino, colo curto e malformações mullerianas também são considerados fatores que aumentam o risco de prematuridade. ${ }^{1}$

Carvalho et $a l . .^{33}$, em 2003, publicaram estudo realizado em nosso serviço no período de março de 1999 a abril de 2000. Avaliaram 529 mulheres sem grupo selecionado, em seguimento de pré-natal de rotina, que foram submetidas à medida do colo uterino por ultrassom transvaginal entre 11-14 semanas e 22-24 semanas. Essas medidas foram comparadas em dois grupos: mulheres que tiveram parto a termo e parto prematuro ( $<37$ semanas). Observaram que a média da medida cervical no primeiro trimestre não foi significativamente diferente nos 2 grupos. Porém, a média da medida cervical no segundo trimestre foi significativamente menor no grupo dos partos prematuros ( $26,7 \mathrm{~mm}$ vs $39,3 \mathrm{~mm}, p=0,0001$ ), associando o colo curto à prematuridade.

\subsubsection{Características da gestação atual}

Diversos fatores presentes na gestação têm sido associados à prematuridade espontânea, devendo ser considerados como sinais de alerta na vigilância pré-natal. São eles: sobredistensão uterina (sendo as principais causas: gestação múltipla, polidrâmnio e macrossomia), infecções (incluindo as cervico-vaginais e outras infecções, além do trato genital como pielonefrite, bacteriúria assintomática, pneumonia, apendicite e doença periodontal), sangramento vaginal, contrações uterinas frequentes, placenta prévia e modificações cervicais, entre outros. ${ }^{1,11,17,34}$ 
Mercer et al. ${ }^{35}$, em 1995, 2929 gestantes entre 23 e 24 semanas foram avaliadas em 10 centros participantes do Maternal Fetal Medicine Units Network of the National Institute of child Health and Human Development, entre outubro de 1992 e julho de 1994. Contrações uterinas por duas semanas foram associados ao parto prematuro espontâneo em nulíparas ( $\mathrm{RR}=2,41$, IC 95\% 1,47-3,94, $p<0,001)$ e multíparas $(\mathrm{RR}=$ 1,62 , IC $95 \% 1,20-2,18, p=0,002$ ). Sangramento vaginal ( primeiro ou segundo trimestre) associou-se à prematuridade apenas nas multíparas ( $\mathrm{RR}=1,62, \mathrm{IC} 95 \%$ $1,22-2,17, p=0,001)$.

Fonseca et $a l .{ }^{36}$, em 1999, publicaram estudo realizado em nosso serviço em que avaliaram a relação entre alterações das contrações uterinas e parto prematuro. $\mathrm{O}$ estudo foi realizado entre 1996 e 1998, com 56 gestantes com risco para parto prematuro, as quais foram submetidas à monitorização externa das contrações uterinas, no período entre 24 e 34 semanas de gestação, duas vezes por semana, por 1 hora. $\mathrm{O}$ teste foi considerado positivo quando o número de contrações era maior ou igual a 4 contrações por hora antes da $30^{\mathrm{a}}$ semana e a 6 contrações por hora após a mesma idade gestacional. A frequência média das contrações foi significativamente maior no grupo dos partos prematuros $(<37$ semanas), com média de 8 contrações por hora nos prematuros e 2 contrações po hora no grupo dos partos a termo, sendo $p<0,05$.

No estudo de Goldenberg et al. $^{19}$, publicado em 1998, foi avaliado possíveis fatores de risco associados à prematuridade espontânea. Foram avaliadas 2929 gestantes que fizeram acompanhamento em 10 centros do National Institute of Child Health and Human Development Maternal Fetal Medicine, entre outubro de 1992 e julho de 1994. Além da associação entre prematuridade espontânea e raça negra citado anteriormente, outros fatores associados à prematuridade foram: contrações uterinas, sangramento 
vaginal, infecção pélvica (incluindo clamídia, gonorréia, sífilis, herpes, fungos ou tricomonas), vaginose bacteriana e colo curto ( $\leq 25 \mathrm{~mm}$ ). O RR para parto prematuro (<37 semanas), com IC 95\%, para esses fatores foram respectivamente 1,8 $(1,4-2,3)$, $1,5(1,1-2,1), 1,3(1,0-1,6), 1,3(0,98-1,6), 3,5(2,7-4,6)$.

Meis et al..$^{37}$, em artigo publicado em 1995, mostraram associação entre parto prematuro ( $<35$ semanas) e infeccções vaginais. Esse estudo deriva do multicêntrico “The Preterm Prediction Study” realizado entre 1992 e 1994. As pacientes (n=2929) foram avaliadas aproximadamente com 24 semanas de gestação (22-24 semanas) e novamente com 28 semanas (26-29 semanas). Quanto à presença de infecções vaginais foram avaliadas: vaginose bacteriana ( $\mathrm{pH}$ vaginal $>4,5$ e coloração gram positiva), tricomonas ( presença de Trichomonas vaginalis visualizada por microscopia em secreção vaginal) e monilíase ( presença de qualquer forma de levedura, brotamento ou hifas em secreção vaginal com adição de hidróxido de potássio 10\%). A taxa de detecção de infecção vaginal com 24 e 28 semanas foram respectivamente $23,4 \%$ e $19,4 \%$ para vaginose bacteriana, $3,3 \%$ e $2,7 \%$ para tricomonas e $21,1 \%$ e $19,5 \%$ para monilíase. Entre as variáveis analisadas, a presença de vaginose bacteriana com 28 semanas associou-se com parto prematuro espontâneo ( OR 1,84, IC 95\% 1,15-2,95, $p<$ 0,01). A detecção de tricomonas ou monília em secreção vaginal não tiveram associação significante com parto prematuro.

Andrews et $a .^{38}$, em 2000, publicaram trabalho derivado do "The Preterm Prediction Study", avaliando a associação entre infecção do trato genito-urinário por Chlamydia trachomatis e parto prematuro espontâneo. Dois grupos foram comparados: grupo caso ( parto prematuro espontâneo $<37$ semanas; $n=190$ ) e grupo controle ( parto $\geq 37$ semanas; $n=190$ ). Amostras de urina foram coletadas com 24 ( entre 22 
semanas e 24 semanas e 6 dias) e 28 semanas de gestação ( entre 27 semanas e 28 semanas e 6 dias) e avaliadas por reação de cadeia de ligase, específica para Chlamydia trachomatis. A frequência de infecção do trato genito-urinário por clamídia no geral foi $11,1 \%$ e $11,9 \%$, respectivamente com 24 e 28 semanas. A infecção do trato genitourinário por clamídia com 24 semanas foi significativamente maior no grupo caso ( $15,8 \%$ vs $6,3 \% ; p=0,003$; OR $=2,8$, IC 95\%, 1,4-5,6). Com 28 semanas não se observou diferença significativa na infeccção do trato genito-urinário por clamídia nos grupo caso e controle.

A associação entre gestações complicadas por malformações fetais e prematuridade também já foi demonstrada. Rasmussen et al. ${ }^{39}$, em 2001, investigaram a relação entre prematuridade e presença de malformações ao nascimento. Utilizaram um banco de dados do “ Programa de defeitos congênitos de Atlanta e região metropolitana", avaliando recém-nascidos entre 1989 e 1995. Entre 264392 lactentes, com idade gestacional conhecida nesse período, 7738 (2,93\%) foram diagnosticados com algum defeito ao nascimento, estando incluídas apenas as malformações maiores. Os prematuros ( $<37$ semanas de gestação) apresentaram uma taxa de defeitos congênito, superior ao dobro da taxa dos nascidos a termo ( $37-41$ semanas), com OR de 2,43, IC 95\% (2,3-2,56). A taxa de defeitos ao nascimento variou conforme a idade gestacional, atingindo um risco máximo entre 29 e 32 semanas, com OR de 3,37, IC $95 \%(3,04-3,73)$.

Também em 2001, Shaw et $a l^{40}$, avaliaram a prevalência de malformações diagnosticadas em fetos e bebês até um ano após o parto, na Califórnia, através de um programa de registro populacional, entre 1984 e 1996, por idade gestacional de nascimento (incluindo os nascidos vivos e óbitos fetais). Observaram uma prevalência 
de defeitos de 8,4\%, IC 95\% $(8,2-8,7)$, nos nascidos até 30 semanas $(n=48955)$, reduzindo a prevalência conforme aumento da idade gestacional de nascimento. Nos nascidos após 37 semanas $(n=2812586)$ a prevalência de defeitos decaiu para $2,1 \%$, IC $95 \%(2,0-2,1)$.

Em 2008, Purisch et al. ${ }^{9}$, realizaram estudo para estimar e comparar o risco relativo de gestações complicadas por uma ou mais malformações congênitas maiores, excluindo os casos com cariótipo alterado. Demonstraram que a presença de malformações congênitas, mesmo na ausência de aneuploidia, está associada com um risco significativamente maior de parto prematuro. Esse estudo realizado em Missouri, incluiu 678693 recém-nascidos únicos e vivos, sendo 675040 fetos sem malformações, 3516 com uma malformação maior (fenda labial ou palatina, anomalias urogenitais, defeitos cardíacos, espinha bífida, onfalocele ou gastrosquise, anomalia traqueoesofágica, agenesia renal e hérnia diafragmática) e 137 com múltiplas malformaçãoes ( mais de uma). Considerando prematuridade abaixo de 37 semanas, o OR ajustado nas gestações com apenas uma malformação foi de 2,6, IC 95\% 2,4-2,8 e com múltiplas malformações ( mais de uma malformação maior) foi de 7,2, IC 95\% 4,711. Nos casos de partos prematuros abaixo de 35 semanas, o risco relativo foi ainda maior, com OR ajustado de 3,1, IC 95\% 2,7-3,6 e OR ajustado de 8,0, IC 95\% 4,6-14,1, nos casos de uma ou múltiplas malformações respectivamente.

De acordo com alguns estudos, os fetos pequenos para a idade gestacional ou com restrição de crescimento também são considerados de risco para parto prematuro ${ }^{41,42}$. No entanto, sabe-se que isso é resultado principalmente das indicações de partos terapêuticos pretermo por intercorrências maternas ou fetais. ${ }^{43}$ 
Ott et al. ${ }^{42}$, em 1997, realizaram estudo retrospectivo para determinar se os nascidos prematuros tinham maior incidência de restrição de crescimento do que os nascidos a termo. Para a análise foram utilizados dados computadorizados de todos nascidos vivos no St. John's Mercy Medical Center entre 1990 e 1991. Utilizaram dados de 1990 para construir uma curva de peso de nascimento por idade gestacional, considerando restritos aqueles recém-nascidos de 1991 com peso abaixo do percentil 10 (P10) da curva por idade gestacional. Também utilizaram para a comparação a curva de Hadlock, considerando como restrição de crescimento os fetos com peso estimado por ultrassom abaixo do P 10 da curva de Hadlock. Após avaliação da idade gestacional do nascimento de 1583 fetos, a taxa de restrição de crescimentos nos prematuros $(<37$ semanas) foi de $6,3 \%$ e nos nascidos a termo, $4 \%$, segundo a curva de St. John's Mercy Medical Center (1990), não estatisticamente significativo. Porém, segundo a curva de Hadlock, a taxa de restrição de crescimento nos prematuros e nos nascidos a termo, foi de 7,9\% e 1,5\% respectivamente. Esse resultado foi significativo com $p<0,00001$.

Morken et $a l{ }^{43}$, em 2006, realizaram estudo para avaliar se esses fetos também estão associados à prematuridade espontânea, ou seja, nascidos por trabalho de parto prematuro ou após rotura prematura de membranas ovulares pretermo. Obsevaram associação entre os fetos pequenos para idade (considerando menos 2 desvios-padrão para o peso esperado para a idade gestacional) e parto prematuro. De um total de 33904 recém-nascidos, 4,3\% dos prematuros eram pequenos para a idade gestacional. O OR ( IC 95\%) para prematuridade foi de 1,6 ( 1,5-1,7), chegando a 3,8 (3,3-4,4) considerando os prematuros espontâneos entre 28 e 31 semanas. Outros estudos ${ }^{44,45}$ também têm mostrado essa associação. 
Gardosi, em 2004, apresentou um artigo de prematuridade e restrição de crescimento, em que traz os resultados de uma análise multivariada de banco de dados em Midlands, incluindo 21069 gestantes, sobre a relação entre prematuridade espontânea ( definida como nascimentos abaixo de 34 semanas) e restrição de crescimento fetal (RCF), definida como peso de nascimento abaixo do percentil 10. O OR ajustado para risco de parto pretermo espontâneo foi de 3,3 e 2,8 nas primíparas e multíparas respectivamente.

A tabela 1 resume os fatores de risco para prematuridade espontânea: 
Tabela 1 - Fatores de risco para prematuridade espontânea (adaptado de Goffinet, $2005^{1}$ )

Fatores individuais, socioeconômicos, psicológicos e comportamentais

Raça negra

Mães jovens ( $<15-19$ anos )

Baixo nível socioeconômico

Violência doméstica

Baixo peso antes da gestação

Estresse, ansiedade e depressão

Tabagismo

\section{História obstétrica e ginecológica}

Parto prematura anterior ou aborto espontâneo no segundo trimestre

História familiar ( fatores genéticos )

Cirurgias em colo uterino/colo curto

Malformações Mullerianas

\section{Características da gestação atual}

Sobredistenção uterina

- gestação múltipla

- polidrâmnio

- macrossomia

Infecções

- cérvico-vaginais

- pielonefrite, bacteriúria assintomática, pneumonia, apendicite, doença periodontal

Placenta prévia

Sangramento vaginal

Contrações uterinas frequentes

Modificações cervicais

Malformações fetais

Restrição de crescimento 


\subsubsection{Polidrâmnio e prematuridade}

O polidrâmnio é considerado um fator de risco para prematuridade devido ao seu reflexo na sobredistensão uterina. McParland et al. ${ }^{34}$, em 2004, publicaram artigo sobre trabalho de parto prematuro e prematuridade, destacando a sobredistensão uterina como etiologia de prematuridade espontânea e incluindo como suas principais causas a gestação múltipla e o polidrâmnio. Igualmente, em 2010, Simmons et al. ${ }^{11}$ descreveram a gestação gemelar, o polidrâmnio e também a macrossomia como fatores relacionados à sobredistensão uterina e prematuridade.

Em 1978, Kirkinen e Jouppila ${ }^{46}$ publicaram estudo clínico sobre a incidência de polidrâmnio e sua associação com parto prematuro, realizado na Universidade de Oulu, na Finlândia. O diagnóstico de polidrâmnio foi baseado em achados clínicos inequívocos, um achado ultrassonográfico típico ( áreas anecóicas intrauterina, interfaces claras, movimentos fetais abundantes, extremidades a uma certa distância do corpo) e, em alguns casos, um exame de raio-X. De um total de 14248 partos realizados no perído de 1972 a 1976, foram diagnosticados 52 casos de polidrâmnio, correspondendo a uma taxa de $0,4 \%$. O parto prematuro ( abaixo de 37 semanas) ocorreu em $37,8 \%$ das gestações únicas e $85,7 \%$ das gestações múltiplas, tendo sido considerado como causa primária de mortalidade em $81,8 \%$ dos casos.

Hill et $a .^{47}$, em estudo publicado em 1987, avaliaram na Mayo Clinic, centro terciário de Southeastern Minnesota, 102 pacientes com diagnóstico de polidrâmnio. Foi considerado polidrâmnio aquelas com maior bolsão vertical (MB), medido por ultrassom, maior ou igual a $8 \mathrm{~cm}$. Avaliaram a causa do polidrâmnio e também os resultados perinatais. Encontraram uma taxa total de partos prematuros de $26,5 \%$. 
Excluindo-se os 5 casos que estavam associados à malformação congênita grave, a taxa de prematuridade associada ao polidrâmnio foi de $21,6 \%$.

Varma et al. ${ }^{48}$, em 1988, publicaram estudo sobre o aumento de líquido amniótico e resultados perinatais, em pacientes do St. George's Hospital, em Londres, realizado entre 1983 e 1986, analisando inicialmente 7725 mulheres com ultrassom entre 32 e 36 semanas. Formaram um grupo de 135 pacientes com polidrâmnio, sendo este definido como MB, maior ou igual a $8 \mathrm{~cm}$, correspondendo a uma taxa de polidrâmnio de $1,7 \%$. No grupo controle foram incluídas 135 gestantes, com líquido normal, considerado como MB entre 2 e $8 \mathrm{~cm}$. Tiveram o parto prematuro, entre 32 e 37 semanas, $11,1 \%$ (15/135) das pacientes com polidrâmnio e 6,7\% (9/135) das pacientes com líquido normal, sendo $p<0,05$. Considerando apenas os casos de trabalho de parto prematuro (TPP) espontâneo, a taxa de prematuridade no grupo polidrâmnio também foi maior do que no grupo controle, sendo 53,3\% (8/15) e 33,3\% (3/9), respectivamente e com $p<$ 0,05 .

Many et $a l .{ }^{49}$, em 1996, estudaram um grupo de 275 gestantes com feto único que apresentaram polidrâmnio, definido como Índice de Líquido Amniótico (ILA) maior que $25 \mathrm{~cm}$, avaliado em um período de 36 meses. A taxa de parto prematuro foi de $18.9 \%$, não havendo diferença estatística entre polidrâmnio leve, moderado e grave. Observou-se que somente os fetos com malformações congênitas e aqueles de mães diabéticas, apresentaram incidência significativamente maior de parto prematuro, em relação ao polidrâmnio idiopático, 39\%, 22,2\% e 12,6\% respectivamente com $p<$ 0,001 .

Chen et $a l{ }^{50}$, em 2005, também publicaram estudo caso-controle, avaliando o polidrâmnio em gestações sem associação com malformações congênitas, acima de 20 
semanas e resultados perinatais. $\mathrm{O}$ estudo foi realizado através de pesquisa de banco de dados do Chang Gung Memorial Hospital, de julho de 1990 a dezembro de 2001. Foi chamado de grupo caso as pacientes com polidrâmnio, definido como ILA $>24 \mathrm{~cm}$ ( $\mathrm{N}=279$ ) e grupo controle, aquelas com líquido normal, considerado como ILA entre 5 e $24 \mathrm{~cm}(\mathrm{~N}=44478)$. Foi considerado parto prematuro aquele que ocorreu antes de 37 semanas. A taxa de parto prematuro no grupo polidrâmnio foi de $25,5 \%$, enquanto que no grupo controle foi de apenas 7,3\%, sendo $p<0,001$.

Pri-Paz et al ${ }^{51}$, em 2012, em estudo de coorte, restrospectivo, realizado entre 2003 e 2008 em centro terciário, avaliaram a associação entre parto prematuro $<34$ semanas e $<37$ semanas e severidade do polidrâmnio. Foram incluídas todas as pacientes que realizaram pelo menos um ultrassom na unidade, gestação única e ILA $\geq 25 \mathrm{~cm}$ ou maior bolsão $\geq 8 \mathrm{~cm}$ mesmo com um ILA $<25 \mathrm{~cm}$, num total de 524 casos. Enquanto não houve nenhum caso de parto $<34$ semanas quando ILA $<25 \mathrm{~cm}$, atingiu-se $19,4 \%$ de partos $<34$ semanas quando ILA $\geq 35 \mathrm{~cm}$. Em relação aos prematuros, considerando idade gestacional inferior a 37 semanas, houve apenas 5 partos $(7,2 \%)$ quando ILA $<$ $25 \mathrm{~cm}$ chegando a 31 partos ( 46,3\%) quando ILA $\geq 35 \mathrm{~cm}$. Esses resultados são estatisticamente significativos, sendo $p<0,005$ e demonstraram associação entre o parto prematuro abaixo de 34 e 37 semanas com a severidade do polidrâmnio.

Taskin et $a .^{52}$, em 2013, publicaram estudo caso-controle, para avaliar polidrâmnio idiopático e resultados perinatais. Polidrâmnio foi definido como ILA $>20$ cm $(n=59)$ e no grupo controle foram incluídos os casos com pelo menos três medidas de ILA entre 5 e $20 \mathrm{~cm}$, após a $20^{\mathrm{a}}$ de gestação $(\mathrm{n}=101)$. Foi considerado como parto prematuro aquele que ocorreu abaixo de 37 semanas. Como resultado obtiveram 
associação estatisticamente positiva com parto prematuro ( $16,5 \%$ vs $5 \% ; p<0,012)$ e com apgar $<7$ no $1^{\circ}$ e $5^{\circ}$ minuto.

Panting-Kemp et $a .^{53}$, em 1999, estudaram a associação entre polidrâmnio idiopático e resultados perinatais, entre eles, a prematuridade. Foram incluídas neste estudo 151 mulheres com gestação única e polidrâmnio idiopático, definido como ILA $>24 \mathrm{~cm}$, acompanhadas no serviço no período de dezembro de 1996 a maio de 1998 . O grupo controle foi constituído de 302 mulheres com líquido normal. Parto prematuro foi definido como abaixo de 37 semanas de gestação. Nesse estudo, porém, não houve associação entre polidrâmnio idiopático e prematuridade, sendo as taxas de partos prematuros no grupo polidrâmnio e controle iguais a 6,6\% e 7,9\% respectivamente.

Smith et $a l .^{54}$, em 1992, publicaram artigo sobre a relação entre polidrâmnio idiopático leve, definido no estudo como ILA entre 24,1 e $39,9 \mathrm{~cm}$ e resultados perinatais. O estudo foi realizado entre 1988 e 1991. Foram avaliadas um total de 1177 pacientes, das quais 97, admitidas para perfil biofísico fetal após 26 semanas, tiveram diagnóstico de polidrâmnio idiopático leve, correspondendo a uma taxa de $8.2 \%$. O grupo controle, para avaliação dos resultados, foi constituído por 462 casos com líquido normal. $\mathrm{Na}$ análise de trabalho de parto prematuro e parto prematuro foram incluídas apenas aquelas pacientes que tinham realizado ultrassom antes de 37 semanas, um total de 46 pacientes no grupo polidrâmnio. A taxa de trabalho de parto prematuro e parto prematuro no grupo polidrâmnio foi a mesma de $8,7 \%$ (4/46), enquanto que no grupo com líquido normal foi 2,6\% (12/462) e 5,8\% (27/462) respectivamente. Neste estudo, apesar de maior no grupo polidrâmnio, não houve diferença estatítica entre os dois grupos, não existindo associação entre polidrâmnio idiopático e trabalho de parto prematuro e parto prematuro. 
Malas et al. ${ }^{55}$, em 2005, também avaliaram a associação entre polidrâmnio idiopático e resultados perinatais. Realizaram um estudo retrospectivo entre julho de 2002 e outubro de 2003, avaliando um total de 2142 pacientes e obtendo um grupo de 69 mulheres, com gestação única e polidrâmnio idiopático ( grupo caso). Foi considerado como polidrâmnio ILA maior que $24 \mathrm{~cm}$. O grupo controle foi formado por 150 gestantes com ILA normal. A taxa de polidrâmnio encontrada foi de 4,8\%. Neste estudo, similarmente a Panting-Kemp ${ }^{53}$ e Smith et al. $^{54}$, não encontraram associação entre polidrâmnio idiopático e parto prematuro abaixo de 37 semanas, tendo ocorrido $6(8.7 \%)$ partos prematuros no grupo caso e 12 (8\%) no grupo controle.

A tabela 2 mostra um resumo dos trabalhos que estudaram o polidrâmnio e a prematuridade. 
Tabela 2 - Estudos que avaliaram a relação entre polidrâmnio e prematuridade

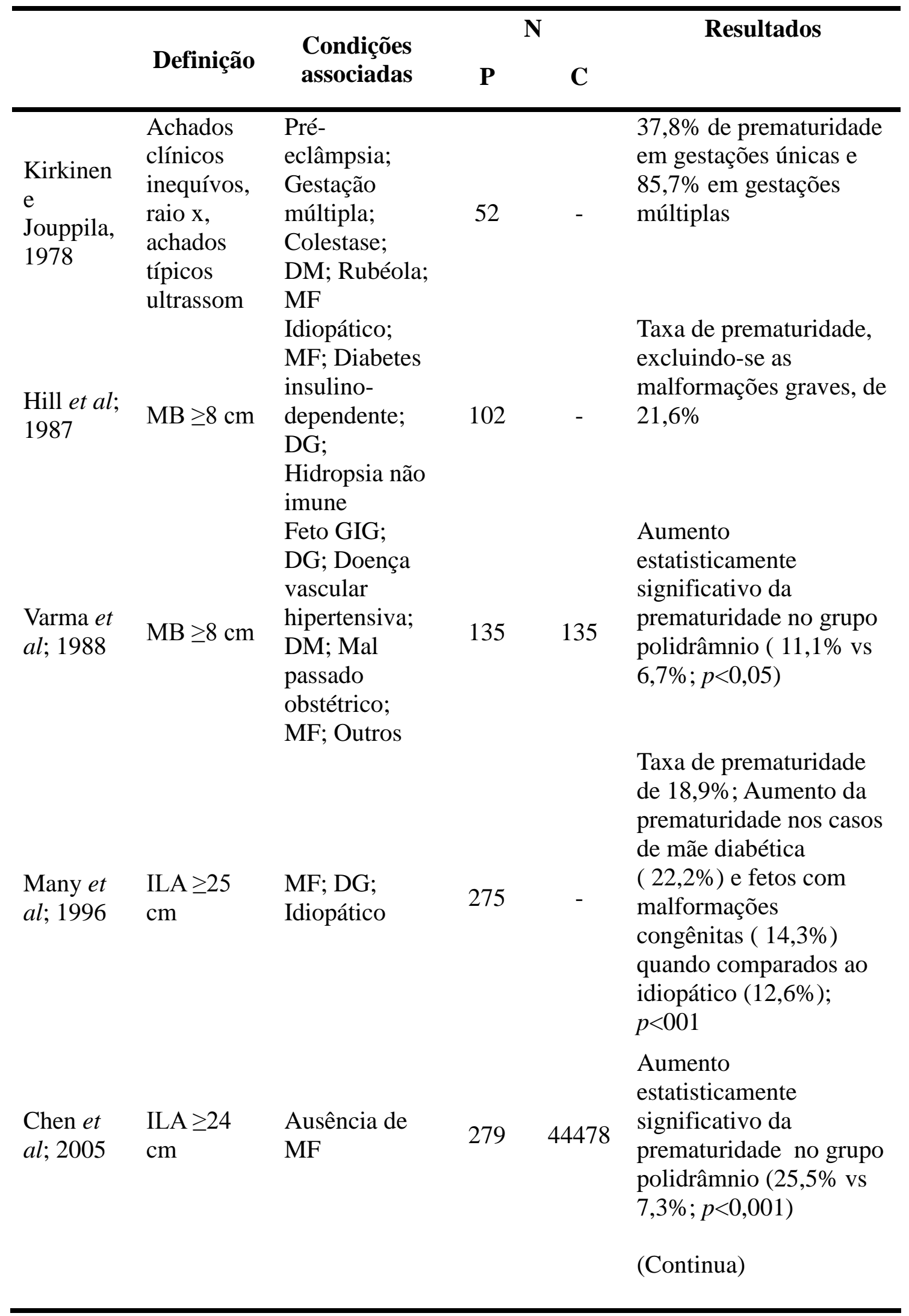




\begin{tabular}{|c|c|c|c|c|c|}
\hline $\begin{array}{l}\text { Pri-Paz et } \\
\text { al; } 2012\end{array}$ & $\begin{array}{l}\text { ILA } \geq 25 \\
\mathrm{~cm} \\
\mathrm{MB} \geq 8 \mathrm{~cm}, \\
\text { mesmoe se } \\
\text { ILA }<25 \\
\mathrm{~cm}\end{array}$ & $\begin{array}{l}\text { MF; DM; } \\
\text { Aneuploidias; } \\
\text { Idiopático; } \\
\text { Outros }\end{array}$ & 524 & - & $\begin{array}{l}\text { Aumento } \\
\text { estatisticamente } \\
\text { significativo da } \\
\text { prematuridade < } 34 \text { e } 37 \\
\text { semanas }(0 \% \text { vs } 19,4 \% \text {; } \\
7,2 \% \text { vs } 46,3 \% ; p \\
<0,005) \text { comparando } \\
\text { ILA }<25 \mathrm{~cm} \text { e ILA } \geq 35 \\
\text { cm }\end{array}$ \\
\hline $\begin{array}{l}\text { Taskin et } \\
\text { al; } 2013\end{array}$ & $\begin{array}{l}\text { ILA } \geq 20 \\
\mathrm{~cm}\end{array}$ & Idiopático & 59 & 101 & $\begin{array}{l}\text { Aumento } \\
\text { estatisticamente } \\
\text { significativo da } \\
\text { prematuridade no grupo } \\
\text { polidrâmnio }(16,5 \% \\
\text { vs } 5 \% ; p<0,012)\end{array}$ \\
\hline $\begin{array}{l}\text { Panting- } \\
\text { Kemp et } \\
\text { al; } 1999\end{array}$ & $\begin{array}{l}\text { ILA } \geq 24 \\
\mathrm{~cm}\end{array}$ & Idiopático & 151 & 302 & $\begin{array}{l}\text { Não houve associação } \\
\text { estatística entre } \\
\text { polidrâmnio e } \\
\text { prematuridade }(6,6 \% \\
\text { prematuros com } \\
\text { polidrâmnio vs } 7,9 \% \\
\text { prematuros no grupo } \\
\text { controle) }\end{array}$ \\
\hline $\begin{array}{l}\text { Smith et } \\
\text { al; } 1992\end{array}$ & $\begin{array}{l}\mathrm{ILA} \geq 24,1 \\
\mathrm{~cm}\end{array}$ & Idiopático & 46 & 462 & $\begin{array}{l}\text { Não houve associação } \\
\text { estatística entre } \\
\text { polidrâmnio e } \\
\text { prematuridade }(8,7 \% \\
\text { prematuros com } \\
\text { polidrâmnio vs } 5,8 \% \\
\text { prematuros no grupo } \\
\text { controle) }\end{array}$ \\
\hline $\begin{array}{l}\text { Malas et } \\
\text { al; } 2005\end{array}$ & $\begin{array}{l}\mathrm{ILA} \geq 24 \\
\mathrm{~cm}\end{array}$ & Idiopático & 69 & 150 & $\begin{array}{l}\text { Não houve associação } \\
\text { estatística entre } \\
\text { polidrâmnio e } \\
\text { prematuridade }(8,7 \% \\
\text { prematuros com } \\
\text { polidrâmnio vs } 8 \% \\
\text { prematuros no grupo } \\
\text { controle) }\end{array}$ \\
\hline $\begin{array}{l}\text { abetes } \\
\text { alforma }\end{array}$ & fetal & $\begin{array}{l}=\text { gr } \\
I G=\end{array}$ & & & $\begin{array}{l}\text { tes gestacional; } \mathrm{DM}= \\
\text { le gestacional; } \mathrm{MF}=\end{array}$ \\
\hline
\end{tabular}


Mazor et al. ${ }^{56}$, em 1996, com o objetivo de determinar a prevalência de polidrâmnio em partos prematuros e gestação única, analisaram o polidrâmnio como fator de risco para mortalidade perinatal e morbidade intraparto nos prematuros. Polidrâmnio foi definido como ILA $>25 \mathrm{~cm}$ ou $\mathrm{MB}>8 \mathrm{~cm}$ ou avaliação subjetiva estimando aumento do líquido amniótico. Foram incluídas 4211 mulheres com gestação única, membranas íntegras e parto prematuro ( entre 23 e 37 semanas), sendo que 210 pacientes (5\%) tinham polidrâmnio. Observou-se que a prevalência de polidrâmnio foi significativamente maior em neonatos pretermos do que naqueles de termo ( $5 \%(210 / 4211)$ vs $1,9 \%$ $(1335 / 71357) ; p<0,001)$.

\subsection{Hérnia diafragmática congênita}

A hérnia diafragmática congênita é uma malformação rara, com prevalência entre 1,7 a 5,7 por 10000 nascimentos, sendo que um terço dos casos associa-se a malformações maiores ${ }^{2,57,58}$.

Embriologicamente consiste em um defeito do diafragma, decorrente do fechamento insuficiente da membrana (septo transverso) que separa o tórax do abdome e ocorre entre a $8^{\mathrm{a}}$ e $12^{\mathrm{a}}$ semana de gestação ${ }^{59}$. A maioria dos defeitos ocorre do lado esquerdo do diafragma ( $87 \%$ ), mas também acomete o lado direito ( $10-11 \%)$ e bilateralmente $(2 \%)^{4,59}$.

A sensibilidade da ultrassonografia para o rastreamento de HDC atinge $60 \%$ na Europa ${ }^{5}$. A maioria dos casos de HDC são esporádicos, porém já foi descrita associação com herança autossômica recessiva ${ }^{60}$. Já foram descritos defeitos de quase todos os cromossomos em pacientes com HDC ${ }^{61}$, merecendo destaque as deleções no 
cromossomo 15 q26 e transloções não balanceadas na região $15 q 24-q 26{ }^{60,61}$. Algumas drogas como talidomida, quininas, drogas anti-epiléticas, nitrofeno e a deficiência de vitamina A têm sido associadas à HDC ${ }^{4,59,60}$. O risco de recorrência dos casos isolados é de aproximadamente $2 \%{ }^{4,62}$.

A HDC pode ser encontrada isoladamente ou, como já dito, associada a outras malformações, incluindo cardíacas, renais, do sistema nervoso central e gastrointestinais, correspondendo a 25 a $57 \%$ dos casos ${ }^{4}$. Também pode associar-se a cromossomopatias.

As alterações cromossômicas mais comumente encontradas são: Trissomia dos cromossomos 21, 18 e 13, sendo descrito também a Síndrome de Turner . Também pode fazer parte de várias síndromes genéticas ${ }^{4,59,60}$, como as Síndromes de Beckwith Wiedeman e Danny Drash ${ }^{59}$.

O diagnóstico pré-natal da HDC com ultrassonografia pode ser feito com sinais diretos, como a presença de órgãos abdominais na cavidade torácica, ou sinais indiretos, como polidrâmnio, eixo cardíaco anormal ou desvio de mediastino. A visualização do diafragma em corte sagital não exclui a anomalia, pois apenas uma região do diafragma pode apresentar o defeito ${ }^{4}$.

A taxa de diagnóstico da hérnia diafragmática congênita isolada, quando comparada com a da hérnia associada a outras malformações, síndromes ou alterações de cariótipo, apresenta uma diferença significativa ( $51 \%$ vs $72 \%){ }^{57}$

O diagnóstico diferencial inclui: malformação adenomatóide cística, sequestro broncopulmonar, eventração diafragmática, cisto broncogênico, cisto entérico e neuroentérico, teratoma mediastinal e atresia brônquica ${ }^{4}$. 


\subsubsection{Fatores prognósticos dos fetos com hérnia diafragmática congênita}

O prognóstico fetal na HDC é afetado pela associação com outras malformações ou anomalias cromossômicas ${ }^{2,63}$. Alguns estudos também sugerem pior prognóstico relacionado à lateralidade da hérnia, à herniação do fígado para o tórax e ao LHR ( lung head ratio).

\subsubsection{Malformações associadas ou anomalias cromossômicas}

Skari et al. ${ }^{2}$, em 2000, publicaram uma metanálise sobre os fatores de mortalidade associados à hérnia diafragmática congênita. Realizaram a busca de trabalhos publicados entre janeiro de 1975 e dezembro de 1998 no banco de dados da Medline, Embase e Cochrane. Selecionaram um total de 51 artigos publicados e dividiram em 3 grupos: 1) Fetos com diagnóstico pré-natal de HDC; 2) Neonatos com HDC admitidos em centro de tratamento e 3) Estudos de base populacional. A frequência de malformações maiores associadas foi de 33,7\%, 23,3\% e 39,5\% nos três grupos respectivamente. Em todos os grupos a associação com malformações maiores foi considerada um importante fator de mortalidade.

Ruano et $a l .^{63}$, em 2006, publicaram trabalho sobre diagnóstico pré-natal e resultados perinatais de 38 casos de HDC, observados em 8 anos de experiência no centro de medicina fetal do nosso serviço. Chegaram a uma taxa de óbito fetal de 41,7\% nos casos de malformação associada com cariótipo normal, 55,6\% nos casos com anomalia cromossômica associada e $0 \%$ na HDC isolada. A mortalidade neonatal precoce foi de $50 \%, 44 \%$ e $76,4 \%$ para os três grupos, respectivamente. Os óbitos 
neonatais precoces foram associados com a presença de outros defeitos estruturais ou anomalias cromossômicas.

\subsubsection{Lado da hérnia}

Em metanálise publicada por Skari et $a{ }^{2}{ }^{2}$, em 2000, foi avaliada a taxa de mortalidade em relação à lateralidade da hérnia. No primeiro grupo avaliado, formado por fetos com diagnóstico pré-natal de HDC, 6 estudos relatavam a mortalidade nos casos de HDC direita e esquerda e não foi encontrada diferença significativa na mortalidade total ( $75 \%$ vs $68,7 \%, p=0,59$ ). No segundo grupo, formado por neonatos com HDC admitidos em centro de tratamento, num total de 7 estudos, a mortalidade foi significativamente maior nos casos de HDC direita do que nos casos de HDC esquerda ( $65,2 \%$ vs $47,1 \%, p=0,006)$. No terceiro grupo, constituído por estudos de base populacional, apenas 2 estudos reportavam às taxas de mortalidade que, no total, a mortalidade também foi significativamente maior nos casos de HDC direita ( 66,7\% vs 23,1\%, $p=0,002)$. Em conclusão, a taxa de mortalidade foi maior nos casos de HDC direita e como não encontraram associação entre o lado da hérnia e a presença de associação com malformações maiores, sugere-se que outras diferenças entre HDC direita e esquerda contribuam nas diferentes taxas de mortalidade.

Datin-Dorriere et al. ${ }^{5}$, em 2008, estudaram 79 casos de nascidos vivos com HDC isolada e com cariótipo normal e os fatores relacionados ao aumento da mortalidade neonatal. Treze $(16,5 \%)$ casos eram de HDC direita e $66(83,5 \%)$ esquerda. Nos casos de HDC direita, 8 morreram e 5 sobreviveram. Na HDC esquerda, 21 casos morreram e 45 sobreviveram. O p , na avaliação do lado da hérnia como risco de mortalidade em 
HDC isolada, foi de 0,011. Observaram que a mortalidade neonatal relacionou-se ao lado da hérnia (direita), à posição intratorácica do estômago e do fígado, ao LHR menor que 1,5 e ao volume pulmonar fetal mensurado por ressonância nuclear magnética (RNM) menor que 30\%. A idade gestacional no momento do diagnóstico ultrassonográfico, polidrâmnio (maior bolsão $\geq 8 \mathrm{~cm}$ ) e a relação ventrículo esquerdo/ventrículo direito no corte das 4 câmaras não se associaram à mortalidade.

Ruano et al. ${ }^{64}$, em 2012, publicaram trabalho sobre resultados neonatais em fetos com HDC isolada, estudando 108 casos avaliados no período de janeiro de 2004 a dezembro de 2010. Um dos parâmetros avaliados foi a lateralidade da hérnia em relação à morte neonatal e à hipertensão arterial pulmonar (HAP) severa após nascimento. Tiveram 82 casos de HDC esquerda e 26 casos de HDC direita. Nos casos de HDC esquerda, $60 \%$ evoluíram com morte neonatal e 58,5 \% com HAP severa. Já nos casos de HDC direita, igualmente 76,9\% evoluíram com morte neonatal e HAP severa. Nesse estudo, essas diferenças não foram consideradas significativamente estatística ( $p$ igual a 0,13 e 0,09 respectivamente) e não associaram a hérnia diafragmática congênita direita ao pior prognóstico.

\subsubsection{Fígado intratorácico}

Na avaliação por Datin-Dorriere et $a l^{5}{ }^{5}$, em 2008, com 79 casos de nascidos vivos com HDC isolada e com cariótipo normal, a posição do fígado intratorácico também se associou significativamente com a mortalidade neonatal. $\mathrm{O}$ risco relativo para risco de mortalidade em HDC isolada ( lado esquerdo), com IC 95\%, foi calculado em 3.14 ( $1.33-7.40)$ e $p$ igual a 0,006 . 
Cannie et $a l .^{65}$, em 2008, publicaram estudo avaliando a quantificação da herniação do fígado intratorárico por imagem de RNM e predição de sobrevida pós natal em fetos com HDC. Foram incluídos 40 fetos com HDC isolada, nascidos vivos após a $32^{\mathrm{a}}$ semana de gestação, vivos em alta hospitalar ou morte pós natal por hipoplasia e/ou hipertensão pulmonar. A RNM foi realizada em média com 30 semanas. A proporção entre entre o volume do fígado herniado na cavidade torácica e o volume total da cavidade torácica (LiTR) foi calculada. A análise de regressão univariada revelou o LiTR como preditor significativo de sobrevivência e a análise de regressão múltipla demonstrou que o LiTR fornece previsão independente de sobrevivência com $p$ igual a 0,003 e 0,024 respectivamente.

Ruano et $a l{ }^{64}$, em 2012, também avaliaram a presença do fígado intratorácico como fator prognóstico nos fetos com HDC isolada. Diferentemente da lateralidade, encontraram associação positiva entre presença de fígado intratorácico e mortalidade neonatal e HAP pulmonar severa pós-natal. Dos 76 casos que tinham fígado intratorácico, 81,5\% evoluíram com morte neonatal e 76,3\% com HAP severa. Esses resultados foram significativos $\operatorname{com} p<0,001$.

\subsubsection{LHR e LHRo/e}

O LHR, como já citado, é considerado um importante indicador prognóstico na HDC e também tem sido apontado na avaliação dos casos candidatos à cirurgia fetal. Sua medida é mensurada pela ultrassonografia, sendo a razão entre a área do pulmão contralateral à hérnia e a circunferência cefálica. A área do pulmão deve ser medida em 
corte transverso do tórax ao nível da imagem 4 câmaras cardíacas, definida como o produto dos dois maiores diâmetros perpendiculares entre si, em milímetros ${ }^{3}$.

Alguns autores sugerem que o LHR possa variar de acordo com a idade gestacional. Por isso atualmente diversos autores propõem a avalição do LHR observado pelo LHR esperado para a idade gestacional (LHRo/e), que pode ser calculado através das fórmulas propostas por Jani et al. ${ }^{66}$, em 2012.

Jani et at. ${ }^{67}$, em 2007, já haviam realizado estudo avaliando o LHR e LHRo/e em fetos normais ( $\mathrm{N}=650)$ e em fetos com HDC isolada ( $\mathrm{N}=354)$. Observaram que tanto o LHR de fetos normais, quanto de fetos com HDC aumentava com a idade gestacional, porém o LHRo/e não mudava significativamente com a idade gestacional. Observaram também que nos fetos normais a mediana dos LHRo/e de ambos os pulmãos foram iguais a $100 \%$ (IC de 95\%), variando de 61 - 139\% no pulmão esquerdo, com $p$ igual a 0,464 e variando de 67 - 133\% no pulmão direito, $\operatorname{com} p$ igual a 0,320 , concluindo que o LHRo/e não mudava significativamente com a idade gestacional. Já nos fetos com HDC isolada, a mediana do LHRo/e foi igual a 36,6, com IC de 95\%, variando de $6.8-$ 79,4\% . A análise de regressão multivariada mostrou que a medida do LHRo/e fornece uma previsão de sobrevivência útil nos fetos com HDC isolada, com OR (IC de 95\%) de $1,09(1,06-1,12)$, e $p$ significativo e $<0,001$.

No trabalho realizado por Ruano et al. ${ }^{64}$, em 2012, com fetos com HDC isolada, tanto o LHR quanto o LHR o/e foram estatisticamente associados ao pior prognóstico através da avaliação de morte neonatal e HAP severa pós-natal. A mediana para o LHR de todos os casos foi $1,40 \pm 0,88$ e para o LHR associado à morte neonatal e HAP severa foi $0,97 \pm 0,31$ e $1.0 \pm 0,7$, com $\mathrm{p}<0,001$ nos dois casos. Já a mediana para o LHRo/e, em porcentagem, de todos os casos foi $24,3 \pm 8,5$ e para o LHRo/e associado à 
morte neonatal e HAP severa, respectivamente foi $20,5 \pm 6,5$ e 21,5 $\pm 8,0$, com $p<$ 0,001 nos dois casos.

Através dos resultados desse trabalho, criaram uma classificação através de parâmetros ultrassonográficos para HDC isolada, que avalia a probabilidade desses fetos de sobrevivência e de desenvolverem HAP severa. Foram considerados extremamente graves, com probabilidade de sobrevivência de até $10 \%$ e de desenvolver HAP severa acima de 70\% fetos com LHR $<0,7$ ou LHRo/e $<15 \%$. Já os casos com LHR $>1,9$ ou LHRo/e $>45 \%$, foram considerados leves com probabilidade de sobrevivência entre 80 e $100 \%$ e de desenvolver HAP severa $<20 \%$.

Outro fator que pode interferir na sobrevida dos fetos com HDC é a prematuridade.

\subsection{Prematuridade e hérnia diafragmática congênita}

Da mesma forma que a prematuridade em geral causa aumento da morbidade e mortalidade neonatal, ela também parece estar associada a um pior prognóstico nos fetos com HDC. Dois estudos até o momento avaliaram a taxa de prematuridade e a sobrevida nesses fetos.

Levison et $a l .{ }^{8}$, em 2006, publicaram um estudo sobre incidência e sobrevivência dos recém-nascidos com HDC em South Wales e Australian Capital Territory, entre os anos de 1992 e 2001. Dos 200 nascidos vivos, a maioria foi de termo (70\%), com taxa de sobrevivência de $64 \%$, e os prematuros ( $30 \%$ ) tiveram apenas $30 \%$ de sobreviventes. A prematuridade foi considerada uma fator de risco independente para a mortalidade com OR de 3.06 (IC de 95\%), variando de 1.57-5.94. Apgar $\leq 5$ no $5^{\circ}$ minuto e 
pneumotórax também foram considerados fatores de risco independentes de mortalidade.

Tsao et al. ${ }^{7}$, em 2010, também estudaram o impacto da prematuridade nos fetos com HDC. Através de um estudo retrospectivo realizado na University of Texas School Houston and Children's Memorial Hermann Hospital, analisaram os bancos de dados de janeiro de 1995 a julho de 2009 de 98 instituições internacionais. Foram incluídos 5069 casos, sendo que $77,6 \%$ nasceram a termo e $22,4 \%$, prematuros. A sobrevida global foi de $68,7 \%$, sendo significativamente maior nos nascidos a termo quando comparados aos prematuros $(73,1 \%$ vs $53,5 \%, p<0,001)$. Os prematuros tiveram maior percentual de fetos com anomalias cromossômicas ( $8,1 \%$ vs $4.0 \% ; p<0,0001)$ e defeitos cardíacos maiores $(11,8 \%$ vs $6,1 \% ; p<0,0001)$. Nos casos em que as crianças foram submetidas ao reparo da hérnia, os nascidos a termo também tiveram uma taxa de sobrevivência significativamente maior que os prematuros ( $84,6 \%$ vs $77,2 \%$ ). Além da prematuridade, anomalias cromossômicas, malformações cardíacas maiores, necessidade de reparo da hérnia e necessidade de oxigenação por membrana extracorpórea (ECMO) foram consideradas variáveis independentes altamente relacionadas com a mortalidade. 
Tabela 3 - Estudos que avaliaram a taxa de prematuridade e sobrevida em fetos portadores de hérnia diafragmática congênita

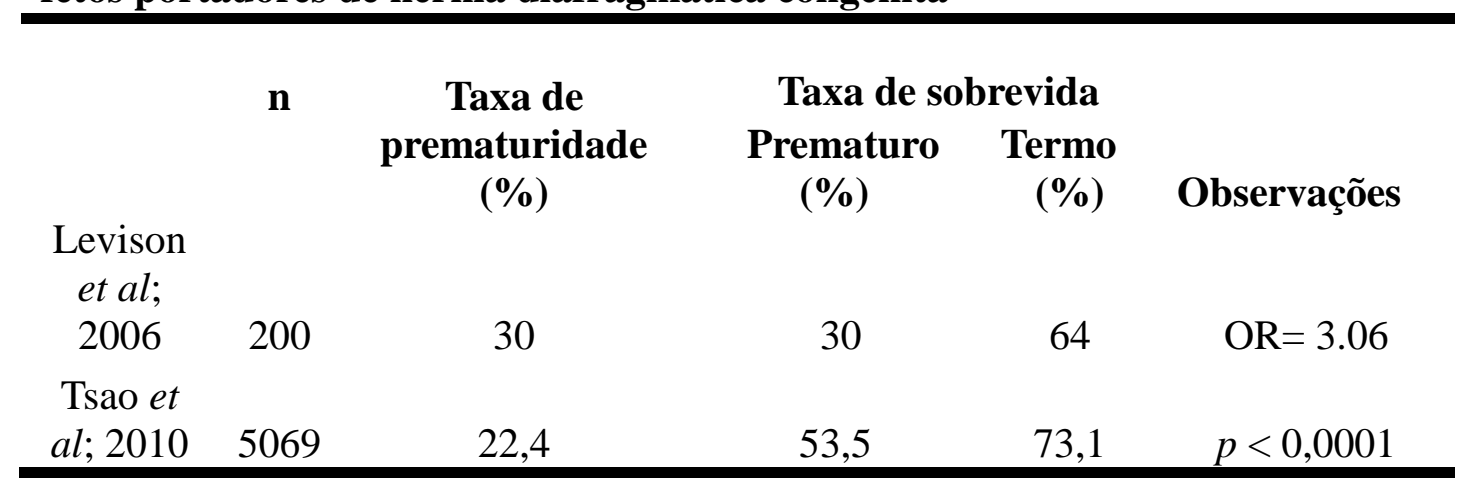

Um outro estudo avaliou a relação entre presença de malformações fetais ( entre elas, a hérnia diafragmática) e prematuridade. Purisch et al. ${ }^{9}$, como citado anteriormente, em 2008, demonstraram que a presença de malformações congênitas, mesmo na ausência de aneuploidia, está associada com um risco significativamente maior de parto prematuro. O estudo realizado em Missouri incluiu 678693 recémnascidos únicos e vivos, sendo 675040 fetos sem malformações, 3516 com uma malformação maior (fenda labial ou palatina, anomalias urogenitais, defeitos cardíacos, espinha bífida, onfalocele ou gastrosquise, anomalia traqueoesofágica, agenesia renal e hérnia diafragmática), sendo que 185 tinham HDC e 137 com múltiplas malformações ( mais de uma). Foi analisada a taxa de prematuridade e o risco de parto pretermo nesses 3 grupos e em cada tipo de malformação maior isoladamente.

A taxa de prematuridade, considerando 37 semanas como termo, foi de 9,7\%, 20,6\%, 41,6\% e 23,1\% nos casos respectivamente sem malformação, com uma, com múltiplas e com HDC. O risco de parto prematuro, considerando a mesma idade gestacional, quando comparado aos casos sem malformações, foi maior nos casos de hérnia diafragmática (OR ajustado 3,2, IC 95\% 2,4-4,3). O risco relativo nos fetos com HDC foi maior que nos casos com uma malformação (OR ajustado 2,6, IC 2,4-2,9) e 
menor que nos casos com múltiplas malformações (OR ajustado 7,2, IC 95\% 4,7-11). No caso de parto prematuro abaixo de 35 semanas, o risco relativo de parto prematuro nos fetos com HDC também foi maior. Na análise multivariada para parto pretermo entre 32-35 semanas, 28-32 semanas e abaixo de 28 semanas, o risco relativo nos casos dos fetos com HDC também foi maior. Esses resultados estão representados na tabela 4: 
Tabela 4 - Risco de parto prematuro por número de malformações congênitas e hérnia diafragmática congênita ( adaptado de Purisch et al., 2008)

\begin{tabular}{lllll}
\hline $\begin{array}{l}\text { Resultado do } \\
\text { nascimento }\end{array}$ & $\begin{array}{l}\text { Sem } \\
\text { malformação } \\
(n=675040)\end{array}$ & $\begin{array}{l}\text { Uma } \\
\text { malformação } \\
(\mathrm{n}=3516)\end{array}$ & $\begin{array}{l}\text { Múltiplas } \\
\text { malformações } \\
(\mathrm{n}=137)\end{array}$ & $\begin{array}{l}\text { Hérnia } \\
\text { diafragmática } \\
\text { congênita } \\
(\mathrm{n}=185)\end{array}$ \\
& (referência) & & & \\
\hline
\end{tabular}

\begin{tabular}{lcccc}
\hline $\begin{array}{l}\text { Parto } \\
\text { prematuro }<37 \\
\text { semanas }\end{array}$ & & & & \\
\hline $\mathrm{n}=66087(9,7)$ & $65304(9,7)$ & $726(20,6)$ & $57(41,6)$ & $42(23,1)$ \\
$\begin{array}{l}\text { OR ajustado (IC } \\
95 \%)\end{array}$ & 1,0 & $2,6(2,4-2,8)$ & $7,2(4,7-11)$ & $3,2(2,4-4,3)$ \\
\end{tabular}

Parto entre 32-

35 semanas

$\begin{array}{lcccc}\mathrm{n}=16817(2,5) & 16590(2,5) & 215(6,1) & 12(8,8) & 10(5,5) \\ \begin{array}{l}\text { OR ajustado (IC } \\ 95 \%)\end{array} & 1,0 & 2,8(2,4-3,3) & 5,1(2,2-11,7) & 2,8(1,8-4,4)\end{array}$

\section{Parto entre 28-}

32 semanas

\begin{tabular}{lcccc}
\hline $\mathrm{n}=7078(1,0)$ & $6969(1,0)$ & $98(2,8)$ & $11(8,0)$ & $6(3,3)$ \\
OR ajustado (IC & 1,0 & $3,2(2,4-4,2)$ & $11,5(7,2-18,4)$ & $4,2(2,4-7,4)$ \\
$95 \%)$ & & &
\end{tabular}

\begin{tabular}{|c|c|c|c|c|}
\hline $\begin{array}{l}\text { Parto entre } 20 \text { - } \\
28 \text { semanas }\end{array}$ & & & & \\
\hline $\mathrm{n}=4073(0,6)$ & $3989(0,6)$ & $75(2,1)$ & $9(6,6)$ & $4(2,2)$ \\
\hline $\begin{array}{c}\text { OR ajustado (IC } \\
95 \%)\end{array}$ & 1,0 & $4,5(3,7-5,5)$ & $15,1(8,0-28,3)$ & $5,2(2-13,7)$ \\
\hline
\end{tabular}

As variáveis estão expressas em números (porcentagem)

Não existem até o momento medidas preventivas para a prematuridade nos fetos com HDC. Também não sabemos ao certo qual a interferência do polidrâmnio na idade gestacional do parto, nem o papel de outros fatores de risco para prematuridade nessa população. Sendo assim, nosso objetivo é avaliar a incidência de prematuridade e 
estudar possíveis fatores de risco para a prematuridade especificamente nos fetos com HDC. Dessa forma, diante de fatores de riscos identificados, talvez possamos intervir para prevenção da prematuridade e diminuir a morbidade e mortalidade associadas a ela. Poderemos também, mais seguramente, programar a melhor idade gestacional para o parto eletivo, com equipes neonatal e cirúrgica especializadas disponíveis para a recepção desses recém nascidos. 


\section{4 - MÉTODOS}




\section{Métodos}

\subsection{Coleta de dados}

Foi realizado levantamento dos prontuários das gestantes com feto portador de hérnia diafragmática que foram acompanhados em nosso serviço de medicina fetal de janeiro de 2001 a outubro de 2014, através do sistema de informática da enfermaria (prontuários eletrônicos), USS e SILOG (sistemas de laudos de ultrassonografia ). Foi realizado contato telefônico com as pacientes cujo parto não tenha sido realizado em nosso serviço para obtenção de seus dados. Este estudo foi aprovado pela Comissão de Ética para Análise de Projetos de Pesquisa (CAPPesp) do Hospital das Clínicas da Faculdade de Medicina da Universidade de São Paulo (HC-FMUSP).

\subsection{Critérios de inclusão:}

1. Gestação única;

2. Feto vivo no momento do parto;

3. Presença de hérnia diafragmática fetal;

4. Ausência de mais de uma malformação maior ( malformações letais, incuráveis ou curáveis, porém com alto risco de sequela grave ou que ocasione um efeito adverso funcional ou social no indivíduo ${ }^{68}$ ) associada à hérnia diafragmática diagnosticada por ultrassonografia;

5. Ausência de alteração de cariótipo;

6. Ausência de realização de fetoscopia;

7. Ausência de prematuridade terapêutica;

8. Dados do parto disponíveis nos sistemas eletrônicos do HC-FMUSP ou 
informados por contato telefônico.

\subsection{Métodos}

\subsubsection{Descrição das variáveis}

\subsubsection{Prematuridade}

Foram considerados prematuros todos os fetos nascidos antes de 37 semanas de gestação, segundo definição da Organização Mundial da Saúde ${ }^{69}$.

\subsubsection{Idade materna}

Idade materna no dia do parto, em anos.

\subsubsection{Idade materna inferior a 19 anos}

Idade materna abaixo de 19 anos completos no dia do parto, em anos.

\subsubsection{Primiparidade}

Definida como pacientes que tinham o primeiro parto decorrente da gestação em estudo.

\subsubsection{Doenças maternas associadas}

Presença de qualquer doença materna pré-gestacional ou intercorrência obstétrica.

\subsubsection{Tabagismo}

Foram consideradas tabagistas as pacientes que referiam fumar durante a gestação. 


\subsubsection{Antecedente de prematuridade espontânea}

Pacientes com história de parto prematuro anterior espontâneo.

\subsubsection{Qualquer malformação}

Presença de qualquer malformação fetal diagnosticada por ultrassonografia, além da hérnia diafragmática congênita.

\subsubsection{Hidropsia fetal}

Acúmulo anormal de líquido nas cavidades serosas e no interstício dos tecidos do feto, podendo haver edema de pele, derrame pleural ou pericárdio e ascite, sendo necessários pelo menos 2 desses achados. ${ }^{70}$

\subsubsection{Polidrâmnio}

Foram avaliados os casos que tiveram polidrâmnio em qualquer momento da gestação e os que tinham polidrâmnio no último ultrassom antes do parto.

Foi considerado como polidrâmnio ILA $\geq 25 \mathrm{~cm}$ ou $\mathrm{MB}>8 \mathrm{~cm}$.

O ILA é medido através da técnica dos quatro quadrantes, descrita pela primeira vez por Phelan et $a l .^{71}$, em 1987. Na aplicação desta técnica dividimos a cavidade uterina em quatro quadrantes, tendo como referência a linha nigrans no eixo longitudinal e a cicatriz umbilical no eixo transversal. Em cada quadrante é medido o diâmetro vertical do maior bolsão do líquido amniótico e o resultado da soma dos quatro quadrantes, em centímetro, é denominado Índice de líquido amniótico (ILA). 


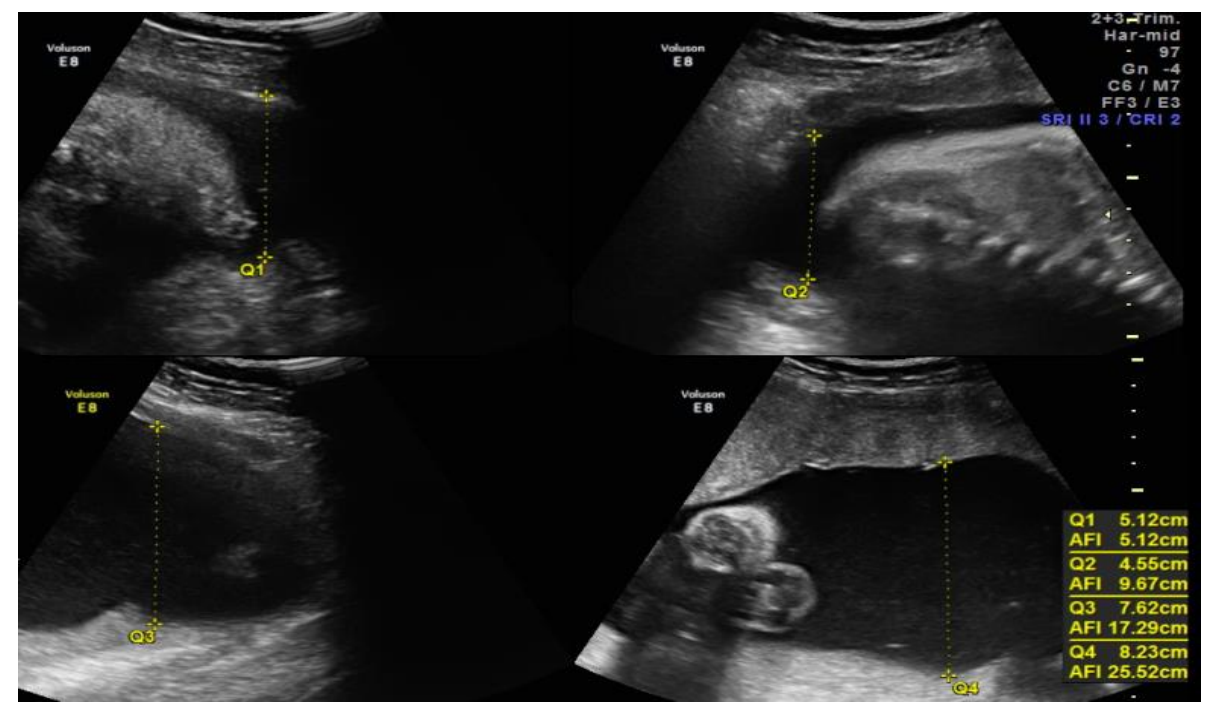

Figura 1 - Técnica dos quatro quadrantes para medida do ILA, descrita por Phelan et al.

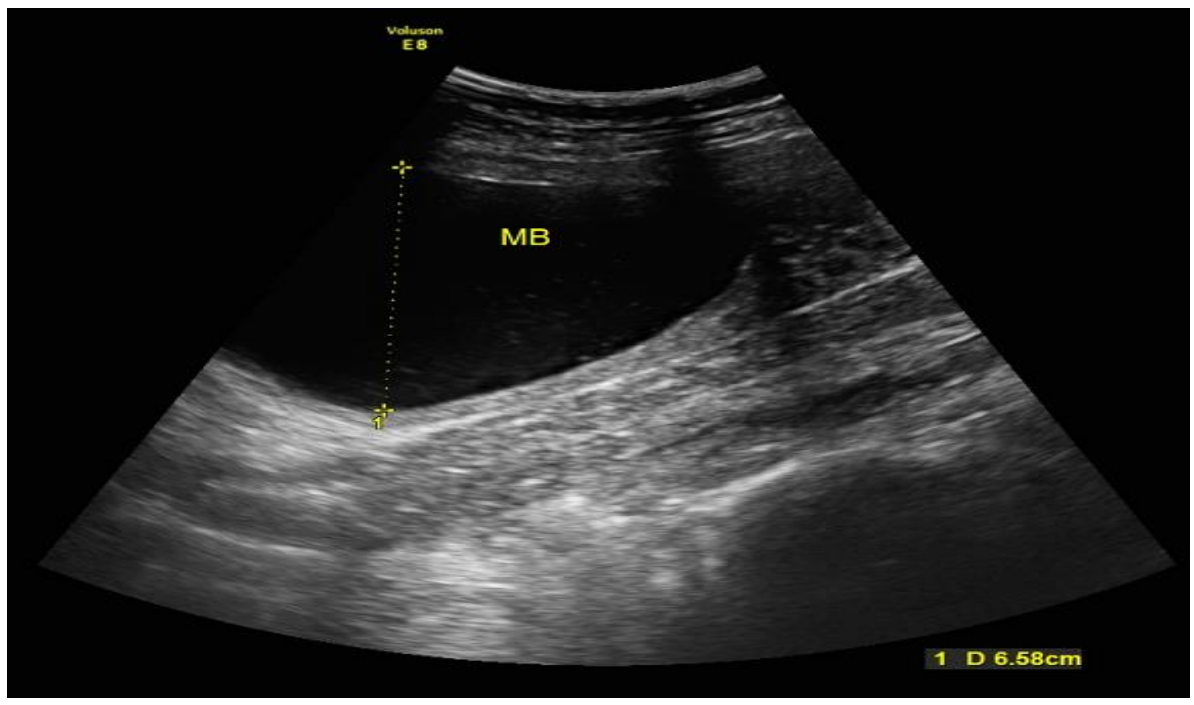

Figura 2 - Medida do maior bolsão vertical

\subsubsection{ILA > 30 no último ultrassom antes de 36 semanas}

Pacientes que apresentavam ILA $>30 \mathrm{~cm}$ no último ultrassom realizado antes de 36 semanas de gestação. 


\subsubsection{Restrição de crescimento fetal}

Segundo definição do nosso serviço, são considerados restritos os fetos com peso fetal estimado abaixo do percentil 10 da curva de Hadlock. O peso fetal foi calculado através da fórmula de Hadlock ${ }^{72}$, utilizando os seguintes parâmetros biométricos: diâmetro biparietal (DBP), circunferência cefálica (CC), circunferência abdominal (CA) e medida do fêmur $(F)$, todos em milímetros.

Foi considerado para essa análise o peso estimado no último ultrassom realizado antes do parto.

\subsubsection{Feto grande para a idade gestacional ( feto GIG)}

Foram considerados fetos $\mathrm{GIG}^{73}$ aqueles com peso fetal estimado acima do percentil 90 da curva de Hadlock, sendo o peso calculado segundo a fórmula de Hadlock, citada anteriormente.

\subsubsection{Presença de fígado intratorácico}

Definido pela visualização total ou parcial do fígado em região torácica. Foi considerado para essa análise o último ultrassom antes do parto.

\subsubsection{Realização de procedimentos invasivos}

Foram considerados os seguintes procedimentos: biópsia de vilo corial, amniocentese diagnóstica, cordocentese, amniodrenagem e dreno tóraco-amniótico.

1) Biópsia de vilo corial via abdominal: procedimento realizado após a $11^{\mathrm{a}}$ semana de gestação, com agulha tipo espinhal, calibre 18 a 20 gauge, sob visão direta e contínua da ultrassonografia, introduzindo a agulha no trofoblasto. São realizados movimentos de vaivém na extensão do córion para a coleta do 
material, que será utilizado para avaliação do cariótipo fetal.

2) Amniocentese diagnóstica ${ }^{74}$ : procedimento realizado sob orientação ultrassonográfica, após 15 semanas de gestação, com agulha de calibre 20 gauge ou 22 gauge, através de punção transamniótica ou transplacentárea para coleta de líquido amniótico e posterior avaliação de cariótipo no líquido amniótico.

3) Cordocentese ${ }^{75}$ : procedimento realizado sob orientação ultrassonográfica, após 20 semanas de gestação, com agulha espinhal com comprimento mínimo de 9 cm e calibre 20 gauge ou 22 gauge, através de punção do vaso umbilical e posterior avaliação do cariótipo no sangue fetal.

4) Amniodrenagem ${ }^{76}$ : procedimento invasivo que consiste na punção percutânea da cavidade amniótica para drenagem de líquido amniótico, para alívio temporário dos sintomas maternos de dispnéia e dor abdominal nos casos de polidrâmnio.

5) Dreno fetal (dreno tóraco-amniótico) ${ }^{77}$ : procedimento guiado por ultrassonografia em que se coloca um catéter para drenar uma coleção anormal de líquido da cavidade fetal para cavidade amniótica.

\subsubsection{Lateralidade}

Definida como lado do defeito diafragmático, hérnia esquerda ou direita.

\subsubsection{LHR observado sobre esperado (LHR o/e)}

A medida do LHR é mensurada pela ultrassonografia, sendo a razão entre a área do pulmão contralateral à hérnia e a circunferência cefálica. A área do pulmão deve ser medida em corte transverso do tórax a nível da imagem 4 câmaras cardíacas, em 
milímetros. Sabe-se que o LHR não é independente da idade gestacional, por isso utilizamos as fórmulas propostas por Jani et al. ${ }^{66}$, em 2012, para corrigir o LHR pela idade gestacional, obtendo-se assim o LHR o/e. Utilizamos para esse cálculo, o primeiro LHR documentado para cada paciente.

$\begin{aligned} & \text { Tabela } 5 \text { - Fórmula para calcular LHR esperado em fetos com hérnia } \\
& \text { diafragmática congênita esquerda e direita, usando o método do maior } \\
& \text { diâmetro, baseado na idade gestacional (IG) em semanas com decimais }\end{aligned}$
\begin{tabular}{lll} 
Medida da área pulmonar & LHR em HDC esquerda & LHR em HDC direita \\
& & \\
Método maior diâmetro & $-3.4802+(0.3995 \times$ & $-2.5957+(0.3043 \times$ \\
& $\mathrm{IG})-\left(0.0048 \times \mathrm{IG}^{2}\right)$ & $\mathrm{IG})-\left(0.0042 \times \mathrm{IG}^{2}\right)$ \\
\hline
\end{tabular}

Modificado de Jani et al. ${ }^{66}$ Ultrasound Obstet Gynecol 2012; 39: 2-6.

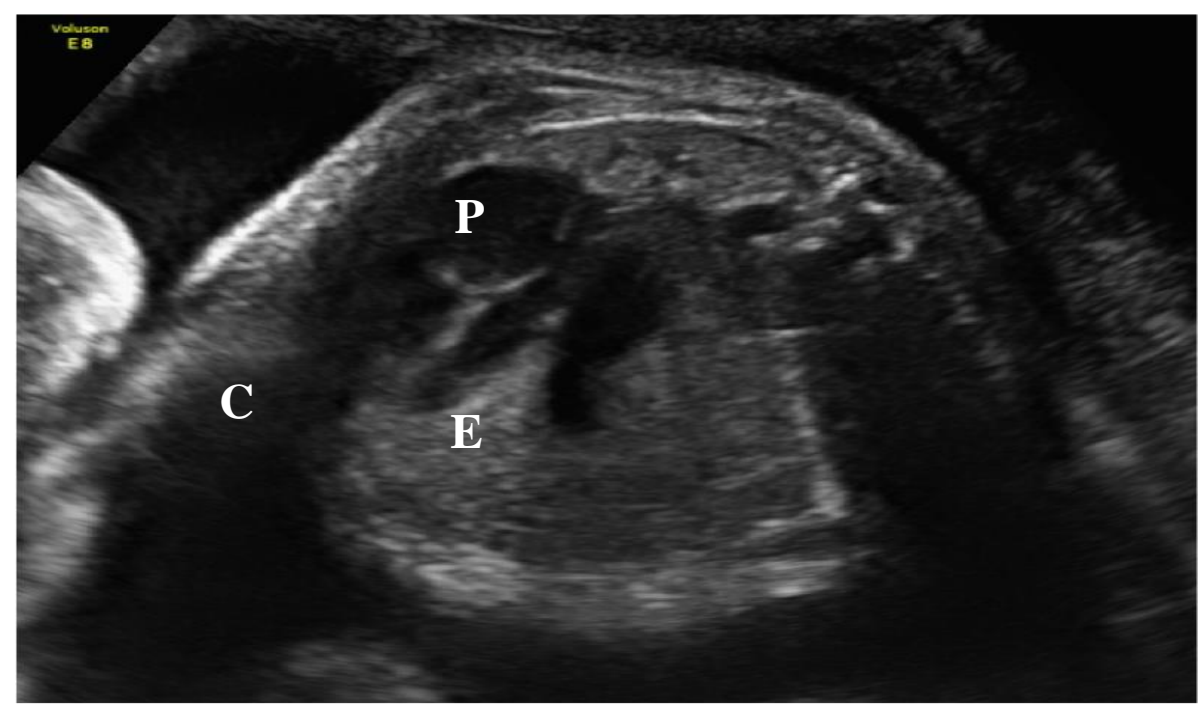

Figura 3 - Corte do tórax a nível de 4 câmaras, em feto portador de hérnia diafragmática esquerda; $\mathrm{P}=$ pulmão; $\mathrm{C}$ = coração; $\mathrm{E}$ = estômago 


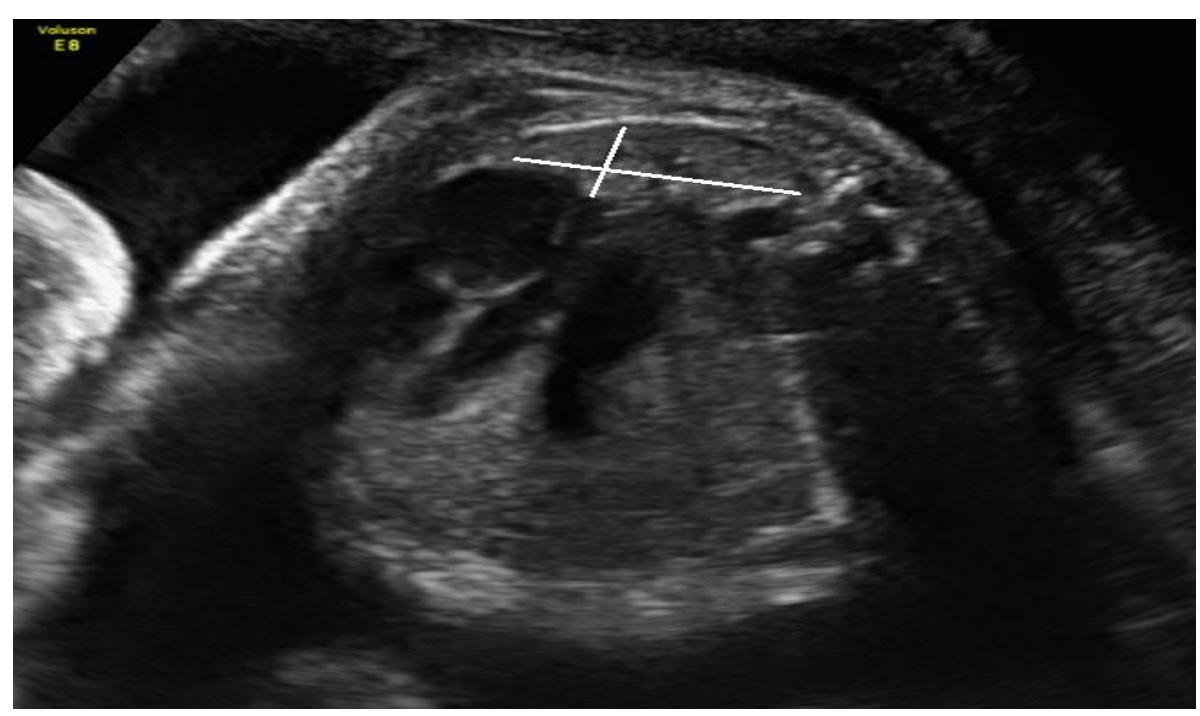

Figura 4 - Medida da área pulmonar pelo método maior diâmetro, do pulmão contralateral à hérnia

\subsubsection{Análise estatística}

Para a descrição dos resultados foram utilizadas as frequências relativas (percentuais) e absolutas (n) das variáveis qualitativas. São elas: idade materna $\leq 19$ anos, doenças maternas associadas, tabagismo, prematuridade espontânea anterior, malformação menor, malformação maior, qualquer malformação, hidropsia fetal, polidrâmnio durante a gestação, polidrâmnio no último ultrassom antes do parto, ILA > $30 \mathrm{~cm}$ no último ultrassom antes de 36 semanas, RCF, feto GIG, fígado intratorácico, realização de procedimentos invasivos, realização de biópsia de vilo, amniocentese ou cordocentese, realização de amniodrenagem, lado da hérnia. Para avaliar associação entre estas e prematuridade foi utilizado o Teste de associação Qui quadrado de Pearson ou teste exato de Fisher quando apropriado. Para as variáveis númericas ( idade materna, LHR o/e) foi utilizado o teste de normalidade de Kolmogorov-Smirnov ${ }^{\text {a }}$ para avaliar a adequabilidade à distribuição normal e por não haver índicios de normalidade, a comparação da prematuridade em relação a essas variáveis foi realizada pelo teste não 
paramétrico de Mann-Whitney. A mediana, valor mínimo e valor máximo foram utilizados para resumir os dados.

Após avaliação individual das variáveis foi ajustado um modelo de regressão logística múltipla (Hosmer \& Lemeshow, 2000) para verificar quais variáveis poderiam influenciam no desfecho de prematuridade. Para a seleção das variáveis no modelo foi utilizado o método de seleção de variáveis stepwise, com nível de significância para selecionar a variável de 0,10 e para remover de 0,20.

Posteriormente construiu-se curva ROC para encontrar um ponto de corte para a(s) variável (is) significativa (s) no modelo de regressão logística com o intuito de predizer a prematuridade nos fetos com hérnia diafragmática, identificando-se o(s) valor(es) com melhor sensibilidade e especifidade a ser usado na prática clínica.

Foram considerados estatisticamente significativos resultados com $p$ menor que 0,05 .

Os dados foram armazenados utilizando planilha eletrônica Excel 2010 e a análise estatística foi realizada utilizando o programa SPSS 20.0 para Windows.

\subsection{Caracterização da população estudada}

Foram avaliadas inicialmente 179 pacientes, das quais 99 não foram incluídas pelos motivos citados a seguir:

- Gestações gemelares ( 6 casos)

- Mais de uma malformação maior associada à hérnia (29 casos)

- Cariótipo alterado ( 14 casos de Trissomia do 18, 2 casos de Trissomia do 13, 1 caso de Síndrome de Down, 1 caso de Síndrome de Turner)

- Diagnóstico de óbito fetal durante o seguimento ( 6 casos)

- Realização de fetoscopia ( 23 casos) 
- Prematuridade terapêutica ( 2 casos)

- Contato telefônico não obtido ( 15 casos)

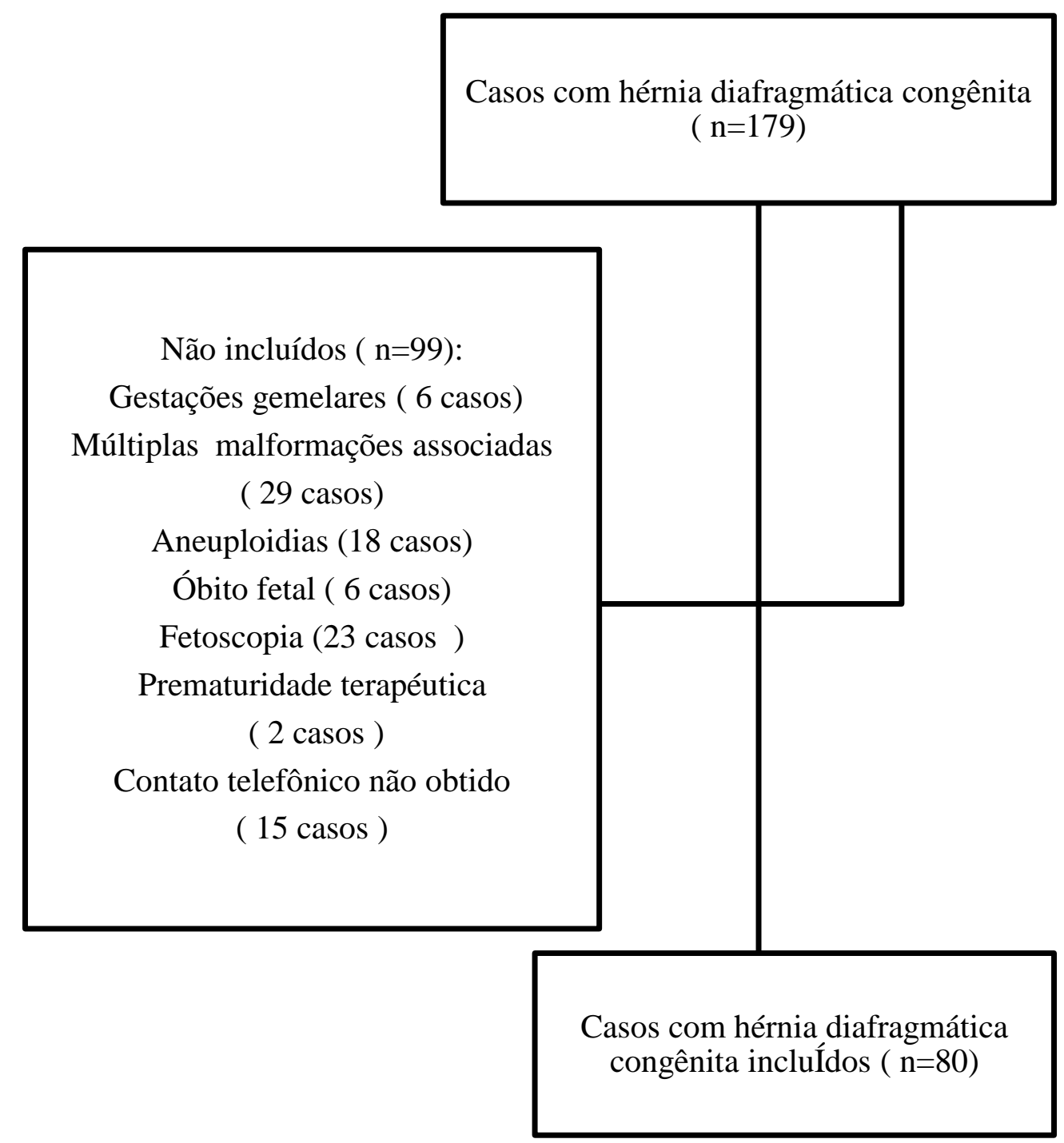

Figura 5 - Fluxograma com a caracterização da população estudada

\subsubsection{Idade materna}

A idade materna variou de 16 a 42 anos, sendo a mediana de 25,5 anos. 


\subsubsection{Número de gestações}

O número de gestações variou de 1 a 7 , sendo a mediana de 2 gestações. No grupo dos nascidos a termo a mediana foi igual a 2, variando de 1 a 6 gestações e no grupo dos prematuros a mediana foi 2 (média 2,1), variando de 1 a 7 gestações.

\subsubsection{Paridade}

A paridade variou de 0 a 6 partos, sendo a mediana de 0 parto.

\subsubsection{Idade gestacional do parto}

A idade gestacional do parto variou de 29,57 a 40,85 semanas, sendo a mediana de 37,85 semanas. A mediana da idade gestacional do parto nos nascidos a termo foi 38,42 semanas, com mínimo de 37 e máximo de 40,85. Nos prematuros, a mediana, mínimo e máximo foram respectivamente 35,42, 29,57 e 36,85 semanas.

\subsubsection{Idade gestacional do início do seguimento no serviço}

A idade gestacional do início do seguimento no serviço ( $1^{\circ}$ ultrassom) variou de 28,17 a 30,63, sendo a média 29,40 semanas, com desvio padrão igual a 5,51. 


\section{5 - RESULTADOS}




\section{Resultados}

\subsection{Incidência de prematuridade nos fetos com de hérnia diafragmática congênita}

Como resultado principal do estudo obtivemos a incidência de prematuridade nos fetos com hérnia diafragmática avaliados. Do total de 80 fetos, 21 nasceram antes de 37 semanas de gestação, correspondendo a uma incidência de 26,25\% de prematuridade.

\subsection{Avaliação de fatores associados à prematuridade}

\subsubsection{Idade materna}

A idade materna variou de 16 a 42 anos, sendo a mediana 25,5 anos. A mediana da idade materna no grupo dos nascidos a termo foi de 24 anos, variando de 16 a 41 anos, e no grupo dos nascidos prematuros a mediana foi de 27 anos, variando de 18 a 42 $\operatorname{anos}(p=0,056)$.

\subsubsection{Idade materna inferior a 19 anos}

Dos nascidos prematuros, 20 mães $(95,2 \%)$ tinham idade $<19$ anos. Dos nascidos a termo, $51(86,4 \%)(p=0,433)$.

\subsubsection{Primiparidade}

Dos prematuros, $7(33,3 \%)$ mães eram primíparas. Dos nascidos a termo, 28 $(47,25 \%)(p=0,203)$ 


\subsubsection{Doenças maternas associadas}

Das 80 pacientes incluídas, $14(21 \%)$ apresentavam comorbidades ou intercorrência obstétrica na gestação atual, sendo: 3 casos de hipertensão arterial crônica; 5 casos de diabetes gestacional, sendo que uma delas apresentou doença hipertensiva específica da gravidez associada; 2 casos de asma; 3 casos de hipotireoidismo, sendo que um desses casos apresentava também retocolite ulcerativa e antecedente de transplante renal; 1 caso de doença hipertensiva específica da gravidez com síndrome em espelho.

Dos 21 casos nascidos prematuros, $18(85,7 \%)$ não apresentavam patologias maternas e $3(14,3 \%)$ apresentavam. Dos 59 nascidos de termo, $48(81,35 \%)$ não apresentavam doenças maternas associadas e 11 (18,65\%) tinham associação com alguma patologia $(p=0,751)$.

\subsubsection{Tabagismo}

Duas $(2,5 \%)$ pacientes relatavam tabagismo. Nenhuma das gestantes dos nascidos prematuros, referia ser tabagista. Dos nascidos a termo duas $(3,38 \%)$ pacientes eram tabagistas $(p=0,999)$.

\subsubsection{Antecedente de prematuridade espontânea}

Três $(3,75 \%)$ pacientes tinham antecedente de prematuridade espontânea. Das gestantes dos nascidos prematuros duas (9,5\%) tinham essa história, as outras 19 ( $80,5 \%$ ) não tinham. Dos gestantes dos nascidos a termo apenas uma (1,7\%) tinha história anterior de prematuridade, os demais 58 (98,3\%) casos não tinham. ( $p=0,167)$. 


\subsubsection{Presença de malformação associada à hérnia}

Vinte e sete $(33,75 \%)$ fetos apresentavam alguma malformação associdada à HDC. Cinco fetos apresentavam pequena comunicação interventricular (CIV),em todos os casos o diagnóstico foi confirmado por ecocardiografia fetal e considerados benignos; três casos de cardiopatias complexas que também foram confirmados por ecocardiografia fetal e passíveis de tratamento cirúrgico pós-natal; dois casos de onfalocele; dois de rim pélvico à esquerda, sendo que um deles apresentava também CIV; dois casos de artéria umbilical única, sendo que um deles apresentava hipoplasia de vermis cerebelar, e outros três casos suspeitos de agenesia de vermis cerebelar; um caso de derrame pleural; um de cisto abdominal; um de rim multicístico à direita; um de hipospádia e um de hidrocefalia.

Dos prematuros, 8 (38\%) tinham alguma malformação e 13 (62\%) tinham hérnia isolada. Dos nascidos a termo, 19 (32,2\%) tinham malformação associada e $40(67,8 \%)$ tinham apenas a hérnia $(p=0,602)$.

\subsubsection{Hidropsia fetal associada}

Cinco $(6,25 \%)$ casos apresentavam hidropsia fetal associada, sendo que 2 deles foram submetidos ao tratamento com dreno tóraco-amniótico e apresentaram reversão do quadro até o final da gestação.

Dos prematuros, $2(9,5 \%)$ apresentaram hidropsia fetal e $19(90,5 \%)$ não tiveram essa intercorrência. Dos nascidos a termo, $3(6,1 \%)$ apresentaram hidropsia fetal e 56 $(94,9 \%)$ evoluíram sem essa alteração $(p=0,602)$. 


\subsubsection{Polidrâmnio}

\subsubsection{Presença de polidrâmnio durante a gestação}

Trinta e dois casos (40\%) apresentavam polidrâmnio em algum momento da gestação. Dos prematuros 7 (33,3\%) apresentavam polidrâmnio e $14(66,7 \%)$ não. Dos nascidos a termo, 25 ( 42,4\%) casos apresentavam polidrâmnio em algum momento da gestação e 34 ( 57,6\%) não apresentavam ( $p=0,606)$.

\subsubsection{Polidrâmnio no último ultrassom antes do parto}

Vinte e quatro casos (30\%) apresentavam polidrâmnio no último ultrassom antes do parto. Dos prematuros, 4 (19\%) apresentavam polidrâmnio e 17 (81\%) não. Dos nascidos a termo, 20 (33,9\%) casos apresentavam polidrâmnio em algum momento da gestação e 39 ( 66,1\%) não apresentavam ( $p=0,272)$.

\subsubsection{ILA maior que $30 \mathrm{~cm}$ no último ultrassom antes de 36 semanas}

Cinquenta $(62,5 \%)$ pacientes apresentavam a medida do ILA no último ultrassom antes de 36 semanas, sendo que $16(32 \%)$ casos nasceram prematuros e $34(68 \%)$ a termo. Dos prematuros, 14 ( 87,5\%) apresentavam ILA menor que $30 \mathrm{cmm}$ e apenas 2 $(12,5 \%)$ tinham o ILA maior que $30 \mathrm{~cm}$. Dos nascidos a termo, $24(70,6 \%)$ tinham ILA menor que $30 \mathrm{~cm}$ e 10 acima desse valor $(29,4 \%)(p=0,292)$.

\subsubsection{Restrição de crescimento fetal}

Vinte e três $(28 \%)$ fetos apresentavam RCF. Dos prematuros, $16(76,2 \%)$ tinham o peso estimado normal e $5(23,8 \%)$ tinham RCF. Dos nascidos a termo, $41(69,5 \%)$ tinham o peso estimado normal e 18 ( $30,5 \%$ ) tinham peso estimado abaixo do percentil 
$10(p=0,780)$.

\subsubsection{Feto GIG no último ultrassom antes do parto}

Três $(3,33 \%)$ fetos apresentaram peso estimado no último ultrassom antes do parto acima do percentil 90. Dos prematuros, 19 (90,5\%) tinham o peso estimado abaixo do $\mathrm{P}$ 90 e apenas $2(9,5 \%)$ eram GIG. Dos nascidos a termo, $58(98,3 \%)$ tinham o peso estimado abaixo do P90 e um ( $1,7 \%)$ era GIG ( $p=0,167)$.

\subsubsection{Presença de fígado intratorácico no último ultrassom antes do parto}

Trinta e cincos $(43,75 \%)$ fetos apresentavam fígado intratorácio. Dos prematuros, 5 $(23,8 \%)$ tinham fígado intratorácico e $16(76,2 \%)$ tinham fígado intra-abdominal. Dos nascidos a termo, $30(50,84 \%)$ tinham o fígado herniado para o tórax e $29(49,15 \%)$ tinham fígado intra-abdominal. $(p=0,041)$.

\subsubsection{Procedimentos invasivos}

\subsubsection{Realização de qualquer procedimento invasivo}

Das 80 pacientes incluídas neste estudo, 32 (40\%) foram submetidas a algum tipo de procedimento invasivo citado a seguir: biópsia de vilo corial, amniocentes, cordocentese, amniodrenagem e dreno de tórax. Dos casos prematuros, 11 (52,4\% foram submetidos a algum procedimento invasivo e $10(47,6 \%)$ não foram. Já dos nascidos a termo $21(35,6 \%)$ realizaram procedimento invasivo e $38(64,4 \%)$ não realizaram $(p=$ $0,203)$. 


\subsubsection{Realização de amniodrenagem}

$\mathrm{Na}$ avaliação das amniodrenagens isoladamente, $6(7,5 \%)$ pacientes foram submetidas à amniodrenagem. Dos prematuros, duas (9,5\%) realizaram amniodrenagem e $19(90,5 \%)$ não realizaram. Dos nascidos a termo, 4 (6,8\%) realizaram amniodrenagem e $55(93,2 \%)$ não foram submetidos a esse procedimento $(p=0,650)$.

\subsubsection{Realização de derivação tóraco-amniótica}

$\mathrm{Na}$ avaliação dos drenos de tórax isoladamente, 2 (2,5\%) fetos foram submetidos ao tratamento com dreno de tórax e ambos nasceram a termo $(3,4 \%)(p=0,999)$.

\subsubsection{Lateralidade da hérnia}

Na avaliação referente à lateralidade da hérnia, em 65 ( 81,25\%) pacientes a hérnia era do lado esquerdo e em 15 (18,75\%), do lado direito. Dos prematuros, 17 (81\%) eram do lado esquerdo e 4 (19\%), do lado direito. Dos nascidos a termo, $48(81,35 \%)$ eram do lado esquerdo e $11(18,65 \%)$, do lado direito $(p=0,999)$.

\subsubsection{LHR o/e}

Das 80 pacientes incluídas no estudo, 56 (70\%) apresentavam pelo menos uma medida de LHR durante a gestação.

A mediana da idade gestacional do primeiro LHR o/e obtido foi 31,28 semanas, variando de 18,71 a 37,85 semanas. Nos prematuros a mediana foi de 29,46 semanas, variando de 18,71 a 35,85 semanas e nos nascidos a termo, a mediana, mínimo e máximo foram respectivamente 31,28, 22,71 e 37,85 semanas ( $p=0,269)$.

A mediana do LHRo/e foi de 34,78\%, variando de $11,33 \%$ a 93,13\%. Quarenta e um $(73,2 \%)$ casos nasceram a termo e quinze $(26,8 \%)$, prematuros. A mediana dos 
partos a termo foi $37,55 \%$ e o mínimo e máximo $11,33 \%$ e $93,13 \%$ respectivamente. A mediana, o mínimo e o máximo dos partos prematuros foi igual a 30,11\%, $17,17 \%$ e 42,56\%, respectivamente. O $p$ é igual a 0,045 e significativo para associação entre LHRo/e e prematuridade.

A tabela 6 mostra os resultados obtidos nas análises estatísticas individuais . 
Tabela 6 - Relação entre diferentes variáveis e prematuridade em 80 fetos com HDC, HC-FMUSP- Janeiro de 2001 a outubro de 2014

\begin{tabular}{|c|c|c|c|}
\hline & maturos $(n=21)$ & Termo $(n=59)$ & $p$ \\
\hline $\begin{array}{l}\text { Idade materna mediana (mín- } \\
\text { máx) }\end{array}$ & $27(18-42)$ & $24(16-41)$ & $\overline{0,056}$ \\
\hline Idade materna $<19$ anos $\mathrm{n}(\%)$ & $20(95,2)$ & $51(86,4)$ & 0,433 \\
\hline Primiparidade n $(\%)$ & $7(33,3)$ & $28(47,45)$ & 0,203 \\
\hline $\begin{array}{l}\text { Doenças maternas associadas } n \\
(\%)\end{array}$ & $3(14,3)$ & $11(18,65)$ & 0,751 \\
\hline Tabagismo n (\%) & $0(0)$ & $2(3,38)$ & 0,999 \\
\hline $\begin{array}{l}\text { Prematuridade espontânea } \\
\text { anterior } \mathrm{n}(\%)\end{array}$ & $2(9,5)$ & $1(1,7)$ & 0,167 \\
\hline $\begin{array}{l}\text { Malformação associada à } \\
\text { hérnia } \\
\mathrm{n}(\%)\end{array}$ & $8(38)$ & $19(32,2)$ & 0,789 \\
\hline Hidropsia fetal n (\%) & $2(9,5)$ & $3(6,1)$ & 0,602 \\
\hline $\begin{array}{l}\text { Presença de polidrâmnio } \\
\text { durante a gestação n (\%) }\end{array}$ & $7(33,3)$ & $25(42,4)$ & 0,606 \\
\hline $\begin{array}{l}\text { Polidrâmnio no último } \\
\text { ultrassom antes do parto n (\%) }\end{array}$ & $4(19)$ & $20(33,9)$ & 0,272 \\
\hline $\begin{array}{l}\text { ILA }>30 \mathrm{~cm} \text { no último } \\
\text { ultrassom antes de } 36 \text { semanas } \\
\mathrm{n}(\%) *\end{array}$ & $2(12,5)$ & $10(29,4)$ & 0,292 \\
\hline $\mathrm{RCF}$ n $(\%)$ & $5(23,8)$ & $18(30,5)$ & 0,780 \\
\hline Feto GIG n (\%) & $2(9,5)$ & $1(1,7)$ & 0,167 \\
\hline Fígado intratorácico n (\%) & $5(23,8)$ & $30(50,84)$ & 0,041 \\
\hline Procedimentos invasivos $\mathrm{n}(\%)$ & $11(52,4)$ & $21(35,6)$ & 0,203 \\
\hline Amniodrenagem n $(\%)$ & $2(9,5)$ & $4(6,8)$ & 0,650 \\
\hline Dreno de tórax n (\%) & $0(0)$ & $2(3,4)$ & 0,999 \\
\hline Hérnia esquerda n (\%) & $17(81)$ & $48(81,35)$ & 0,999 \\
\hline $\begin{array}{l}\text { LHR o/e mediana (mín- } \\
\text { máx)** }\end{array}$ & $30,11(17,2-42,5)$ & $37,55(11,3-93,1)$ & 0,045 \\
\hline
\end{tabular}

$* \mathrm{n}=16$ (prematuros), $\mathrm{n}=34$ (termo)

$* * \mathrm{n}=15$ (prematuros), $\mathrm{n}=41$ (termo)

Após a avaliação inicial, foi ajustado um modelo de regressão logística considerando o desfecho prematuridade como variável resposta e como covariáveis: idade materna, primiparidade, doenças maternas associadas, prematuridade anterior 
espontânea, malformações associadas, hidropsia fetal, polidrâmnio durante a gestação, polidrâmnio no último ultrassom antes do parto, RCF, feto GIG, presença de fígado intratorácico, procedimentos invasivos, LHRo/e. Após a seleção de variáveis, apenas o LHRo/e foi significativo a um nível de significância de 5\% e é a única covariável que permanece no modelo final. Na Tabela 7 estão os resultados do ajuste do modelo final. Assim, pelo modelo final, a probabilidade estimada de parto prematuro, $\hat{p}$, é dada por:

$$
\hat{p}=\frac{\exp \left(\hat{b}_{0}+\hat{b}_{1} * L H R o / e\right)}{1+\exp \left(\hat{b}_{0}+\hat{b}_{1} * L H R o / e\right)}
$$

em que $\hat{b}_{0}$ é o valor do intercepto na coluna $\hat{b}$ da tabela 8 (no caso deste modelo, $\hat{b}_{0}=1,188$ ) e $\hat{b}_{1}$ é o valor de " LHRo/e " da coluna $\hat{b}$ da tabela 8 (no caso deste modelo, $\left.\hat{b}_{1}=-0,059\right)$. Pode-se observar que a cada diminuição de uma unidade no LHRo/e há um aumento de $6,38 \%$ na chance de prematuridade.

\begin{tabular}{|c|c|c|c|c|}
\hline Variável & $\begin{array}{l}\text { Coeficiente } \\
(\hat{b})\end{array}$ & $\begin{array}{l}\text { Odds Ratio } \\
\text { (OR) }\end{array}$ & OR (IC 95\%) & $p$ \\
\hline Intercepto & 1,188 & 3,282 & $(1,369-7,861)$ & 0,174 \\
\hline LHRo/e & $-0,059$ & 0,943 & $(0,919-0,966)$ & 0,020 \\
\hline
\end{tabular}

A curva ROC representada pela figura 6 mostra os valores de sensibilidade e 1especifidade para diferentes pontos de corte de LHRo/e para predição de prematuridade em fetos com HDC. A área sob a curva é 0,676 , indicando um bom ajuste, $\operatorname{com} p=$ 0,045 do teste cuja hipótese nula é de que a verdadeira área sob a curva é igual a 0,50 e como o $p$ é menor que 0,05 , rejeitamos essa hipótese. Na Tabela 8 estão os valores de sensibilidade e especificidade para alguns pontos de corte do LHRo/e. 


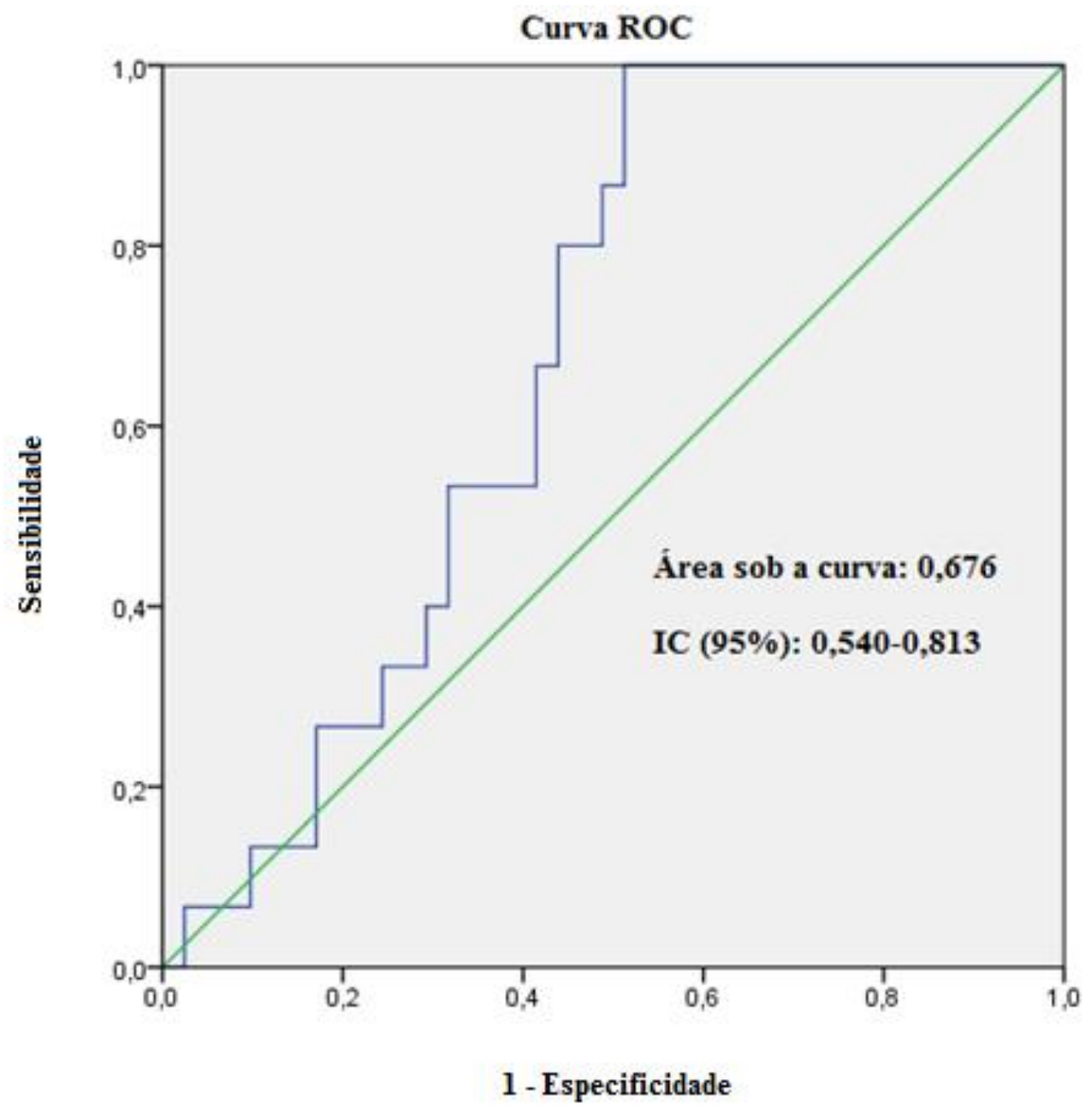

Figura 6 - Curva ROC do LHRo/e para predição de prematuridade IC: intervalo de confiança 
Tabela 8- Sensibilidade e especificidade do LHRo/e para predição da prematuridade em fetos com HDC, HC-FMUSP- Janeiro de 2001 a outubro de 2014

\begin{tabular}{ccc}
\hline LHRo/e (\%) & Sensibilidade (\%) & Especificidade (\%) \\
\hline 20 & 6,7 & 95,1 \\
25 & 26,7 & 78,0 \\
30 & 46,7 & 68,3 \\
35 & 73,3 & 56,1 \\
40 & 93,3 & 48,8 \\
45 & 100 & 43,9 \\
50 & 100 & 39 \\
55 & 100 & 31,7 \\
\hline
\end{tabular}


6 - DISCUSSÃO 


\section{Discussão}

A importância clínica do diagnóstico do risco para parto prematuro consiste na possibilidade de prevenção, para tentar-se aumentar o número de dias da gestação e reduzir a morbidade e mortalidade associadas à prematuridade. A prematuridade nos fetos com hérnia diafragmática congênita tem sido pouco estudada, mas alguns estudos têm mostrado que a incidência de prematuridade nesses fetos é maior que na população em geral ${ }^{7-9}$ e que, a sobrevida nesses recém-nascidos é menor nos prematuros do que nos nascidos a termo ${ }^{7,8}$.

A predição do parto prematuro especificamente em fetos com HDC não foi estudada anteriormente. Sendo assim, estudamos características maternas e características da gestação avaliadas anteriormente na população em geral e também alguns fatores específicos dos fetos com HDC possíveis de associação com prematuridade.

\subsection{Incidência de prematuridade}

A incidência de prematuridade encontrada no nosso estudo foi de $26,25 \%$, que é alta quando comparada aos dados apresentados, em 2005, pelo Sistema de Informações sobre Nascidos Vivos (SINASC - criado no Brasil a partir do Grupo de Estatísticas

Vitais $)^{78}$ que apresentou uma taxa de prematuridade em geral no Brasil de $6,6 \%$. Comparado à taxa de prematuridade em fetos com hérnia diafragmática por outros autores o nosso resultado é semelhante ao encontrado na literatura. Levison et al. ${ }^{8}$, em 2006 e Tsao et $a l^{7}$, em 2010, em trabalhos em que avaliaram a incidência de prematuridade e sobrevida dos recém-nascidos com HDC, obtiveram valores 
semelhantes ao nosso, com taxas de prematuridade iguais a $30 \%$ e $22,4 \%$ respectivamente. Nosso resultado também é semelhante ao encontrado por Purisch et $a l{ }^{9}$, em 2008, que avaliaram o parto prematuro complicado por malformações maiores e encontraram uma taxa de $23,1 \%$ nos fetos com HDC.

\subsection{Fatores preditores de prematuridade}

\subsubsection{LHRo/e}

$\mathrm{Na}$ avaliação de possíveis fatores preditores para prematuridade nessa população o único fator encontrado após análise multivariada foi o LHRo/e. O LHRo/e e o LHR são utilizados na prática clínica como indicadores de prognóstico fetal e na seleção de casos para o tratamento endoscópico com balão. Segundo Jani et al. ${ }^{67}$, em 2007 e Ruano et $a l .^{64}$, em 2012, quanto menor os valores de LHRo/e ou LHR pior será o prognóstico fetal. Apesar de considerado um importante fator na avaliação de prognóstico desses fetos não encontramos na literatura nenhum estudo avaliando esse fator na predição de prematuridade.

Observamos que na avaliação inicial houve associação significativa entre o LHRo/e e a prematuridade ( $p=0,045$ ), associação que se manteve, tornando-se ainda mais forte, após análise de regressão logística ( $p=0,02)$. Não se sabe ao certo o mecanismo fisiopatológico relacionado ao LHRo/e que predisporia à prematuridade. Um possível hipótese é que fetos com hérnia diafragmática de pior prognóstico teriam maior associação com polidrâmnio, o que causaria maior sobredistensão uterina e predisposição à prematuridade. No entanto, estudos que avaliaram o polidrâmnio como fator prognóstico não encontraram essa associação ${ }^{5,64,79}$ e em nossa casuística os fetos com polidrâmnio não tiveram maior prevalência de prematuridade que os fetos com 
quantidade de líquido aminiótico normal, o que faz com que essa hipótese torne-se menos provável.

Outra possível hipótese é que a relação entre LHR o/e e prematuridade deva-se à presença de hipoplasia pulmonar presente nesses fetos, pois sabe-se que menores valores de LHRo/e estão associados ao maior grau de hipoplasia pulmonar. No estudo de Purisch et al. ${ }^{9}$, em 2008, foi avaliado o risco de parto prematuro, comparando os casos com uma malformação, com casos com múltiplas malformações e com 8 tipos de malformação maior isoladamente. A agenesia renal foi a malformação que apresentou o maior risco para parto prematuro, com OR de 6,1 ( IC 95\% 4,3-8,5), e fetos com agenesia renal não têm sobredistensão uterina, podendo, de forma contrária, ter altura uterina diminuída em relação à gestações de fetos sem malformação pela presença de oligoidrâmnio. A HDC e a agenesia renal são malformações que classicamente cursam com hipoplasia pulmonar. Nao sabemos ao certo quais mecanismos na hipoplasia pulmonar fetal poderiam levar ao desencadeamento de prematuridade, mas talvez algum mecanismo comum possa explicar o maior risco de prematuridade desses fetos, e isso pode ser a base para que se iniciem novos estudos de mecanismo fisiopatológico.

A análise da curva ROC permitiu estabeler altos valores de sensibilidade e especificidade intermediária, que podem ser utilizados na prática clínica para avaliação do risco de prematuridade. Pensando-se nas medidas de prevenção em geral existentes, como o uso da progesterona que é usada atualmente na prevenção do parto prematuro nas pacientes com antecedente de prematuridade ${ }^{80,81}$, poderíamos adotar um corte alto na curva ROC, em que a sensibilidade se aproxima de 100\%. Desta forma, poderíamos pensar em estudar um tratamento preventivo, pois tais medidas são de baixo risco para a gestação. 


\subsubsection{Idade materna}

Alguns estudos ${ }^{1,23}$ têm demonstrado risco maior para prematuridade em gestações cuja idade materna seja inferior a 18-19 anos, porém não encontramos este resultado no nosso trabalho. A idade materna inicialmente mostrou uma tendência de associação com prematuridade, porém após a análise por regressão logística este resultado não foi significativo.

\subsubsection{Paridade}

Os estudos em relação à associação entre paridade e parto pretermo parecem ser conflitantes. Embora Ananth et $a .^{22}$, em 2007, tenham encontrado resultado significativo para parto prematuro nas primíparas, em estudo anterior realizado em 2005 por Meis et $a .^{23}$, a associação encontrada foi tanto nas nulíparas como nas multíparas. No nosso estudo essa associação não foi significativa.

\subsubsection{Doenças maternas associadas}

Sabe-se que o parto prematuro pode ser resultado de causas espontâneas como o TPP e a RPMO pretermo ou de causa iatrogênica, resultado de decisão médica indicados por problemas materno ou fetal. Autores ${ }^{43,82}$ apontam que as doenças hipertensivas estão entre as mais comuns indicações de interrupção da gestação prematuramente. Mas em relação ao parto prematuro espontâneo, os trabalhos ${ }^{1,17,83}$ não têm citado relação entre doenças hipertensivas ou outras patologias maternas e prematuridade. Nosso estudo se propôs a avaliar a prematuridade espontânea e não encontrou associação entre a presença de doenças maternas associadas e o parto pretermo. 


\subsubsection{Tabagismo}

Quanto ao tabagismo trata-se de um fator classicamente associado ao parto prematuro espontâneo. Castles et al. $^{27}$, em 1999, em metanálise constataram forte associação entre tabagismo e rotura prematura de membranas ovulares pretermo espontânea, sendo que a avaliação da RPMO mostrou um OR de 1,81, IC 95\% 1,36 2,25, comparando gestantes fumantes com não fumantes. Meis et al. ${ }^{23}$, em 1995, também demonstraram aumento da prematuridade progressivo de acordo com o número de cigarros fumados por dia. O nosso estudo, no entanto, não evidenciou associação entre tabagismo e prematuridade. Isso pode ser explicado pelo número muito pequeno de gestantes que referiam tabagismo $(n=2 ; 2 \%)$.

\subsubsection{Antecedente de prematuridade}

A história de parto prematuro anterior ou de perdas no segundo trimestre, segundo alguns autores, foi considerada o principal fator de risco para prematuridade depois de ajustado os fatores de confusão ${ }^{19,20,28}$. Outros estudos também têm mostrado que a história de parto prematuro espontâneo aumento o risco de prematuridade na gestação atual, em relação às gestantes com parto a termo anterior ${ }^{29-31}$.

Similarmente ao resultado obtido em relação ao tabagismo, também não encontramos associação estatística do antecedente de parto pretermo espontâneo com prematuridade e acreditamos que isso também seja decorrente do número muito restritosde casos com antecedente de prematuridade $(n=3 ; 3,75 \%)$ em nossa amostra.

\subsubsection{Malformação associada à hérnia}

A presença de outra malformação associada à hérnia não se associou ao parto prematuro. No estudo já citado de Purish et al. ${ }^{9}$ de 2008, foi avaliado o risco de parto 
prematuro, comparando os casos com uma malformação, com múltiplas malformações e com HDC isolada aos casos sem malformações. O risco relativo de prematuridade nos fetos com múltiplas malformações foi maior (OR ajustado 7,2, IC 95\% 4,7-11) do que nos fetos com HDC congênita isolada (OR ajustado 3,2, IC 95\% 2,4-4,3). Nesse estudo entretanto foram considerados como fetos com múltiplas malformações, todos os fetos que apresentavam mais de uma malformação maior (fenda labial ou palatina, anomalias urogenitais, defeitos cardíacos, espinha bífida, onfalocele ou gastrosquise, anomalia traqueoesofágica, agenesia renal e hérnia diafragmática). Já no nosso trabalho foram considerados como malformações associadas qualquer tipo de malformação incluindo pequenos defeitos como CIV, artéria umbilical única, hipospádia, entre outros, e no caso de malformação maior associada à hérnia, restringimos o número a apenas um. Ou seja, o critério de inclusão de malformações associadas adotado em nosso trabalho difere daquele utilizado pelo autor citado.

\subsubsection{Hidropsia fetal}

Em relação à avaliação da relação entre presença de hidropsia fetal e prematuridade, não encontramos dados na literatura. No nosso trabalho não houve associação estatística entre essas duas variáveis. Porém, apenas 5 (6,25\%) fetos apresentaram hidropsia no decorrer da gestação, sendo que ainda 2 deles tiveram o quadro revertido antes do término da gestação devido ao tratamento com dreno tóracoamniótico. 


\subsubsection{Polidrâmnio}

Muitos estudos ${ }^{48-52}$ já demonstraram associação significativa entre polidrâmnio e prematuridade. No geral eles incluíram diversas condições associadas ao polidrâmnio, como diabetes pré-gestacional e gestacional, aneuploidia fetal, malformações fetais, feto grande para a idade gestacional, doença vascular hipertensiva, mal passado obstétrico, hidropsia não imune e polidrâmnio de causa idiopática. Outros estudos ${ }^{53-55}$, diferentemente, que incluíram apenas os casos de polidrâmnio idiopático não encontraram associação estatística com a prematuridade.

Nenhum estudo anteriormente havia avaliado a influência do polidrâmnio especificamente nos casos de fetos com hérnia diafragmática congênita na idade gestacional do parto. O nosso trabalho não estabeleceu associação significativa entre polidrâmnio e prematuridade. No entanto, como este resultado difere do discutido na literatura, sugerimos que outros estudos, preferencialmente prospectivos, multicêntricos, com maior número de casos sejam realizados com o intuito de confirmar ou não esses resultados.

\subsubsection{Fígado intratorácico e lado da hérnia}

Optamos por avaliar a presença de fígado intratorácio e o lado da hérnia por serem fatores associados ao prognóstico nesses fetos. No entanto, não há estudos disponíveis que avaliaram a associação desses fatores com a prematuridade. No nosso estudo essa associação não foi significativa.

\subsubsection{Restrição de crescimento fetal}

A RCF, segundo trabalhos publicados por Ott et $a l^{42}$, em 1993 e Morken et al. ${ }^{43}$, em 2006, está associada estatisticamente ao parto prematuro espontâneo. Diversos 
outros estudos ${ }^{41,44,45}$ também têm mostrado essa associação, no entanto, não há trabalhos disponíveis na literatura que tenham estudado a associação entre RCF e prematuridade especificamente em fetos com HDC ou com alguma malformação. No nosso trabalho essa relação não teve significado estatístico e como dito, não dispomos de dados para compararmos com o resultado encontrado.

\subsubsection{Feto grande para a idade gestacional}

Simmons ${ }^{11}$, em 2010, relaciona os fetos GIG à prematuridade devido a influência da sobredistensão uterina presente nas gestações desses fetos. Não encontramos essa associação no nosso trabalho. Porém devemos considerar que tivemos um número baixíssimo de fetos GIG ( $\mathrm{n}=3 ; 3,33 \%)$ na nossa amostra.

\subsubsection{Realização de procedimentos invasivos}

Sabe-se que entre as possíveis complicações dos procedimentos invasivos para fins diagnósticos pré-natal estão o TPP e a RPMO. Essas intercorrências, no entanto, não são citadas pelos estudos cujo objetivo é avaliar os fatores de risco para a prematuridade. Apesar de Cederholm et al. ${ }^{84}$, em 2003, apresentarem um pequeno risco de RPMO após a realização da amniocentese, o OR ajustado observado foi apenas 1,14 e ainda, a idade gestacional da rotura não foi avaliada. Outros estudos ${ }^{85,86}$ também têm mostrado que esses procedimentos apresentam baixas taxas de complicação. Nossa análise não estabeleceu associação entre a realização de procedimentos invasivos e a prematuridade, o que parece ser compatível com as baixas taxas de complicações que esses procedimentos apresentam. Acreditamos que para obtermos um resultado associado a prematuridade, seria necessário uma amostra bem maior. 


\subsubsection{Limitações e considerações finais}

Uma limitação do nosso trabalho foi que por tratar-se de estudo retrospectivo, alguns fatores de associação descritos na população em geral, tais como, raça, nível socioeconômico, características psicológicas materna, história familiar, comprimento do colo uterino, infecções do trato genito-urinário, presença de sangramento ou contrações frequentes na gestação atual e modificações do colo uterino não puderam ser analisados devido à falta de dados no prontuário.

Através do nosso estudo o LHRo/e pode, pela primeira vez, ser considerado um fator preditor de prematuridade em fetos com HDC. Não sabemos ao certo o mecanismo de influência do LHRo/e na ocorrência do parto pretermo. Novos estudos são necessários para consolidar este resultado, tentar compreender a fisiopatologia desse acontecimento e também testar medidas terapêuticas eficazes que possam evitar o parto prematuro e suas complicações nesses fetos, já tão comprometidos pelo seu defeito primário. 


\section{7 - CONCLUSÕES}




\section{Conclusões}

O presente estudo nos permitiu concluir que:

1) A incidência de prematuridade em fetos com hérnia diafragmática congênita foi de $26,25 \%$;

2) Após análise por regressão logística, o LHRo/e foi considerado fator preditor de prematuridade nessa população. 
8 - ANEXO 


\title{
8. Anexo
}

\section{Anexo 1: Aprovação pela Comissão de Ética para Análise de Pesquisa (CAPPesq)}

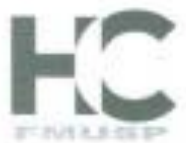

\author{
Hospital das Clínicas da FMUSP \\ Comissão de Ética para Análise de Projetos de Pesquisa - CAPPesq
}

\section{PROJETO DE PESQUISA}

TITULO: FSTUCO DA PQEMATURIDADE NOS FETOS PORTADORES DE HERNIA DIAERAGMATICA CONGENITA: CORRELACAO ENTRE A QUANTIDADE DE LIOUUIOO AMNIOTICO E A IDADE GESTACIONAL DO PARTO

Pesquisador Responsàvel: Lisandra Stein Bernardes Campi Versão: 1

de Andrade

Pesquisador Executante: Bruna Maria Lopes Barbosa CAAE: 15562713.4.0000.0068

Co-autores: Rodrigo Ruano, Roberto Eduardo Bittar, Rossana Pulcineli Vieira Francisco.

Marcelo Zugail

Orientador: Lisandra Stein Bernardes Ciampi de Andrade

Instituiçăos HCFMUSP

Departamento: OBSTETRICLA E GINECOLDGIA

\section{PARECER CONSUBSTANCIADO DO CEP}

Registro on-line: 10707

Nủmero do Parecer: 352.907

Data da Relatoria: 07/08/2013

Apresentaça do Projeto: Trats-se de projeto que avaliarb hernia diafragmática congênito (HDC), mallormaça fetal potenciaimente grave, que cursa com mortalidade em torno de $30 \%$, sendo que dos neonatos que apresentam hernia diafrasmatica, cerca de $2 / 3$ tem sev diagnostico realizado na vida intrauterina. Os autores afirmam que o diagndstico pre natal permite a acompanhamento dos fotos e reallzaço ob parto em centro terciário, com equipe de neonatoiogia e cirureia infanti preparadas para 0 recebimento e cuidados desses necnatos. Porem, embora a prematuridade seja um significante fator de risco para morbidade e mortalidade neonatal na maioria das doenças, sua relachlo com HDC pouco tem sido descrita of que uma das causas de trabalho de parto prematuro e o polidramnic. Nos fetos portadores de HDC, a causa da prematuridade năo \& bem estabelecida, mas sabe-se que nesses fetos $\mathrm{h}$ maior incidência de polidramnio. 5endo assim, o estudo pretende auslist se há correloçẳ entre a quantidade de liquido amniótico e a idade gestacianal do parto em fetos com hèrnia diafragmbtica. De acordo com os autores, este pode set a primeiro passo para buscar a prevençala da prematuridade e diminuir a morbidade associada a ela

Objetho da Pesquisa: $O$ estudo tem par objetho avalar a incidència de prematuridade em fetos portatores de hérnia diafragmatica por meio da medida do colo uterino realizada entro 20 e 24 semanas e da carrelaça entre a idade gestacional do parto nessas pacientes e o indice de llquido aminiotico.

Avaliaçoo dos Riscos e Beneficios: Nalo há riscos ou beneficios.

Comentários e Consideraçóes sobre a Pesquisa: O projeto está bem escrito, tem bons fundamentas teoricos. Os autores irlo rever pronfuabios de pacientes com fetos portadores de hèrnia diafragmática com foco nes paràmetros descritos acima.

Rus Dr, Ovidio Pires de Campos, 225 - Prédla da Administraç\$a - 52 andar

CEP 05403.010 - 5Jo Paulo - SP.

$55112661-7585$ - $55112661-6442$ ramaks: $16,17,18$ I marciacarvalhe Dhe fm.usp br 


\section{Hospital das Clínicas da FMUSP}

Comissăo de Ética para Análise de Projetos de Pesquisa - CAPPesq

Consideraçōes sobre as Termos de apresentação obrigeatória: Há dispensa do TCLE.

Recomendaçōes: Aprovar a projeto

Conclusbles ou Pendénclas e Lusta de Inadequaçóes: Aprovar o projeto

Situaçăo do Parecer: Aprovado

Necessita Apreciacaึด da CONEP; Nâ้

Consideraçăes Finais a crituerio do CEP: Em conformidade com a Resoluçào CNS n9 $466 / 12$ cabe ao pesquisador: a) deservolver o projeto conforme delinesdo; b) elaborar e apresentar relatórios parciais e final; clapresentar dados solicitados pelo CEP, a quaiquer momento; d) manter em arguivo sob sua guarda, por 5 anos da pesquisa, contendo fichas individuais e todos os demais documentos recomendados pelo CEP; e) encaminhar as resultados para publicaçăo, com os devidas créditos sos pesquisadores associados e ao pessaal técnico participante do projeto; f) justificar perante ao CEP interrupçăo do projeto ou a näo publicaço dos tesultados.

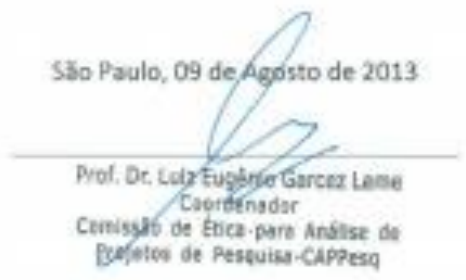

Rua Dr, Ovidio Pires de Campos, 225 - Prédio da Administraçăo - 52 andar CEP 05403-010 - SBo Pasilo-SP.

S5 11 2661-7585-55 $112661-6442$ ramais: $16,17,18$ | marcia.carvalhoeghc.fm. usp.be 


\section{9 - REFERÊNCIAS}




\section{Referências}

1. Goffinet F. Primary predictors of preterm labour. Bjog-an International Journal of Obstetrics and Gynaecology 2005; 112: 38-47.

2. Skari H, Bjornland K, Haugen G, Egeland T, Emblem R. Congenital diaphragmatic hernia: A meta-analysis of mortality factors. Journal of Pediatric Surgery 2000; 35(8): 1187-97.

3. Ba'ath ME, Jesudason EC, Losty PD. How useful is the lung-to-head ratio in predicting outcome in the fetus with congenital diaphragmatic hernia? A systematic review and meta-analysis. Ultrasound in Obstetrics \& Gynecology 2007; 30(6): 897906.

4. Graham G, Devine PC. Antenatal diagnosis of congenital diaphragmatic hernia. Seminars in Perinatology 2005; 29(2): 69-76.

5. Datin-Dorriere V, Rouzies S, Taupin P, et al. Prenatal prognosis in isolated congenital diaphragmatic hernia. American Journal of Obstetrics and Gynecology 2008; 198(1).

6. Simonsen SE, Lyon JL, Stanford JB, Porucznik CA, Esplin MS, Varner MW. Risk factors for recurrent preterm birth in multiparous Utah women: a historical cohort study. Bjog-an International Journal of Obstetrics and Gynaecology 2013; 120(7): 86372 .

7. Tsao K, Allison ND, Harting MT, Lally PA, Lally KP. Congenital diaphragmatic hernia in the preterm infant. Surgery 2010; 148(2): 404-10.

8. Levison J, Halliday R, Holland AJA, et al. A population-based study of congenital diaphragmatic hernia outcome in New South Wales and the Australian Capital Territory, Australia,, 1992-2001. Journal of Pediatric Surgery 2006; 41(6): 104953.

9. Purisch SE, DeFranco EA, Muglia LJ, Odibo AO, Stamilio DM. Preterm birth in pregnancies complicated by major congenital malformations: a population-based study. American Journal of Obstetrics and Gynecology 2008; 199(3).

10. Hedrick HL. Management of prenatally diagnosed congenital diaphragmatic hernia. Seminars in Pediatric Surgery 2013; 22(1): 37-43.

11. Simmons LE, Rubens CE, Darmstadt GL, Gravett MG. Preventing Preterm Birth and Neonatal Mortality: Exploring the Epidemiology, Causes, and Interventions. Seminars in Perinatology 2010; 34(6): 408-15.

12. Blencowe $\mathrm{H}$, Cousens $\mathrm{S}$, Oestergaard $\mathrm{MZ}$, et al. National, regional, and 
worldwide estimates of preterm birth rates in the year 2010 with time trends since 1990 for selected countries: a systematic analysis and implications. Lancet 2012; 379(9832): 2162-72.

13. Wen SW, Smith G, Yang Q, Walker M. Epidemiology of preterm birth and neonatal outcome. Semin Fetal Neonatal Med 2004; 9(6): 429-35.

14. Bhattacharya S, Raja EA, Mirazo ER, et al. Inherited Predisposition to Spontaneous Preterm Delivery. Obstetrics and Gynecology 2010; 115(6): 1125-33.

15. Saigal S, Doyle LW. Preterm birth 3 - An overview of mortality and sequelae of preterm birth from infancy to adulthood. Lancet 2008; 371(9608): 261-9.

16. McIntire DD, Leveno KJ. Neonatal mortality and morbidity rates in late preterm births compared with births at term. Obstetrics and Gynecology 2008; 111(1): 35-41.

17. Goldenberg RL, Culhane JF, Iams JD, Romero R. Preterm birth 1 Epidemiology and causes of preterm birth. Lancet 2008; 371(9606): 75-84.

18. Copper RL, Goldenberg RL, Das A, et al. The preterm prediction study: Maternal stress is associated with spontaneous preterm birth at less than thirty-five weeks' gestation. American Journal of Obstetrics and Gynecology 1996; 175(5): 128692.

19. Goldenberg RL, Iams JD, Mercer BM, et al. The preterm prediction study: The value of new vs standard risk factors in predicting early and all spontaneous preterm births. American Journal of Public Health 1998; 88(2): 233-8.

20. Berkowitz GS, Papiernik E. EPIDEMIOLOGY OF PRETERM BIRTH. Epidemiologic Reviews 1993; 15(2): 414-43.

21. Papiernik E, Alexander GR, Paneth N. RACIAL-DIFFERENCES IN PREGNANCY DURATION AND ITS IMPLICATIONS FOR PERINATAL-CARE. Medical Hypotheses 1990; 33(3): 181-6.

22. Ananth CV, Peltier MR, Getahun D, Kirby RS, Vintzileos AM. Primiparity: An 'intermediate' risk group for spontaneous and medically indicated preterm birth. Journal of Maternal-Fetal \& Neonatal Medicine 2007; 20(8): 605-11.

23. Meis PJ, Michielutte R, Peters TJ, et al. Factors associated with preterm birth in cardiff, Wales .1. Univariable and multivariable analysis. American Journal of Obstetrics and Gynecology 1995; 173(2): 590-6.

24. Berkowitz GS, Kasl SV. The role of psychosocial factors in spontaneous preterm delivery. J Psychosom Res 1983; 27(4): 283-90.

25. Haram K, Mortensen JHS, Wollen AL. Preterm delivery: an overview. Acta Obstetricia Et Gynecologica Scandinavica 2003; 82(8): 687-704.

26. Ebrahim SH, Floyd RL, Merritt RK, Decoufle P, Holtzman D. Trends in 
pregnancy-related smoking rates in the United States, 1987-1996. Jama-Journal of the American Medical Association 2000; 283(3): 361-6.

27. Castles A, Adams EK, Melvin CL, Kelsch C, Boulton ML. Effects of smoking during pregnancy - Five meta-analyses. American Journal of Preventive Medicine 1999; 16(3): 208-15.

28. Papierni.E, Kaminski M. Multifactorial study of risk of prematurity at 32 weeks of gestation .1. Study of frequency of 30 predictive characteristics. Journal of Perinatal Medicine 1974; 2(1): 30-6.

29. Iams JD, Goldenberg RL, Mercer BM, et al. The Preterm Prediction Study: Recurrence risk of spontaneous preterm birth. American Journal of Obstetrics and Gynecology 1998; 178(5): 1035-40.

30. McManemy J, Cooke E, Amon E, Leet T. Recurrence risk for preterm delivery. American Journal of Obstetrics and Gynecology 2007; 196(6): 576-7.

31. Esplin MS, O'Brien E, Fraser A, et al. Estimating recurrence of spontaneous preterm delivery. Obstetrics and Gynecology 2008; 112(3): 516-23.

32. de Carvalho MHB, Bittar RE, Brzt MD, Bicudo C, Zugaib M. Prediction of preterm delivery in the second trimester. Obstetrics and Gynecology 2005; 105(3): 5326.

33. Carvalho MHB, Bittar RE, Brizot ML, Maganha PPS, Borges ESV, Zugaib M. Cervical length at 11-14 week's and 22-24 week's gestation ealuated by transvaginal sonography, and gestational age at delivery. Ultrasound Obstet Gynecol, 2003. ( accessed)

34. McParland P, Jones G, Taylor D. Preterm labour and prematurity. Current Obstetrics \& Gynaecology 2004; 14(5): 309-19.

35. Mercer BM, Goldenberg RL, Das A, et al. The preterm prediction study: A clinical risk assessment system. American Journal of Obstetrics and Gynecology 1996; 174(6): 1885-93.

36. Fonseca ESB, Bittar RE, Zugaib M. Prevenção do nascimento prematuro: importância da monitorização das contrações uterinas. RBGO, 1999. (accessed)

37. Meis PJ, Goldenberg RL, Mercer B, et al. The preterm prediction study Significance of vaginal infections. American Journal of Obstetrics and Gynecology 1995; 173(4): 1231-5.

38. Andrews WW, Goldenberg RL, Mercer B, et al. The Preterm Prediction Study: Association of second-trimester genitourinary chlamydia infection with subsequent spontaneous preterm birth. American Journal of Obstetrics and Gynecology 2000; 183(3): 662-8. 
39. Rasmussen SA, Moore CA, Paulozzi LJ, Rhodenhiser EP. Risk for birth defects among premature infants: A population-based study. Journal of Pediatrics 2001; 138(5): 668-73.

40. Shaw GM, Savitz DA, Nelson V, Thorp JM. Role of structural birth defects in preterm delivery. Paediatric and Perinatal Epidemiology 2001; 15(2): 106-9.

41. Goldenberg RL, Nelson KG, Koski JF, Cutter GR. Low birth-weight, intrauterine growth-retardation, and preterm delivery. American Journal of Obstetrics and Gynecology 1985; 152(8): 980-4.

42. Ott WJ. Intrauterine growth-retardation and preterm delivery. American Journal of Obstetrics and Gynecology 1993; 168(6): 1710-7.

43. Morken N-H, Kallen K, Jacobsson B. Fetal growth and onset of delivery: A nationwide population-based study of preterm infants. American Journal of Obstetrics and Gynecology 2006; 195(1): 154-61.

44. Zeitlin J, Ancel PY, Saurel-Cubizolles MJ, Papiernik E. The relationship between intrauterine growth restriction and preterm delivery: an empirical approach using data from a European case-control study. British Journal of Obstetrics and Gynaecology 2000; 107(6): 750-8.

45. Bukowski R, Gahn D, Denning J, Saade G. Impairment of growth in fetuses destined to deliver preterm. American Journal of Obstetrics and Gynecology 2001; 185(2): 463-7.

46. Kirkinen P, Jouppila P. Polyhydramnion - Clinical-study. Annales Chirurgiae Et Gynaecologiae 1978; 67(3): 117-22.

47. Hill LM, Breckle R, Thomas ML, Fries JK. Polyhydramnios - Ultrasonically detected prevalence and neonatal outcome. Obstetrics and Gynecology 1987; 69(1): 215 .

48. Varma TR, Bateman S, Patel RH, Chamberlain GVP, Pillai U. The relationship of increased amniotic-fluid volume to perinatal outcome. International Journal of Gynecology \& Obstetrics 1988; 27(3): 327-33.

49. Many A, Hill LM, Lazebnik N, Martin JG. The association between polyhydramnios and preterm delivery. Obstetrics and Gynecology 1995; 86(3): 389-91.

50. Chen $\mathrm{KC}$, Liou JD, Hung $\mathrm{TH}$, et al. Perinatal outcomes of polyhydramnios without associated congenital fetal anomalies after the gestational age of 20 weeks. Chang Gung Med J 2005; 28(4): 222-8.

51. Pri-Paz S, Khalek N, Fuchs KM, Simpson LL. Maximal amniotic fluid index as a prognostic factor in pregnancies complicated by polyhydramnios. Ultrasound in 
Obstetrics \& Gynecology 2012; 39(6): 648-53.

52. Taskin S, Pabuccu EG, Kanmaz AG, Kahraman K, Kurtay G. Perinatal outcomes of idiopathic polyhydramnios. Interv Med Appl Sci 2013; 5(1): 21-5.

53. Panting-Kemp A, Nguyen T, Chang E, Quillen E, Castro L. Idiopathic polyhydramnios and perinatal outcome. American Journal of Obstetrics and Gynecology 1999; 181(5): 1079-82.

54. Smith CV, Plambeck RD, Rayburn WF, Albaugh KJ. Relation of mild idiopathic polyhydramnios to perinatal outcome. Obstetrics and Gynecology 1992; 79(3): 387-9.

55. Malas NOM, Jayousi TMM, Miqdadi MF, Ma'ani WeOM. Perinatal Outcome in Idiopathic Polyhydramnios Bahrain Medical Bulletin 2005; 27: 195-9.

56. Mazor M, Ghezzi F, Maymon E, et al. Polyhydramnios is an independent risk factor for perinatal mortality and intrapartum morbidity in preterm delivery. European Journal of Obstetrics Gynecology and Reproductive Biology 1996; 70(1): 41-7.

57. Garne E, Haeusler M, Barisic I, et al. Congenital diaphragmatic hernia: evaluation of prenatal diagnosis in 20 European regions. Ultrasound in Obstetrics \& Gynecology 2002; 19(4): 329-33.

58. Gallot D, Coste K, Francannet C, et al. Antenatal detection and impact on outcome of congenital diaphragmatic hernia: A 12-year experience in Auvergne (France). European Journal of Obstetrics Gynecology and Reproductive Biology 2006; 125(2): 202-5.

59. Waag K-L, Loff S, Zahn K, et al. Congenital diaphragmatic hernia: a modern day approach. Seminars in Pediatric Surgery 2008; 17(4): 244-54.

60. Beck C, Alkasi O, Nikischin W, et al. Congenital diaphragmatic hernia, etiology and management, a 10-year analysis of a single center. Archives of Gynecology and Obstetrics 2008; 277(1): 55-63.

61. Klaassens M, de Klein A, Tibboel D. The etiology of congenital diaphragmatic hernia: Still largely unknown? European Journal of Medical Genetics 2009; 52(5): 2816.

62. Holder AM, Klaassens M, Tibboel D, de Klein A, Lee B, Scott DA. Genetic factors in congenital diaphragmatic hernia. American Journal of Human Genetics 2007; 80(5): $825-45$.

63. Ruano R, Bunduki V, Silva MM, et al. Prenatal diagnosis and perinatal outcome of 38 cases with congenital diaphragmatic hernia: 8-year experience of a tertiary Brazilian center. Clinics (Sao Paulo) 2006; 61(3): 197-202.

64. Ruano R, Takashi E, da Silva MM, Campos JADB, Tannuri U, Zugaib M. 
Prediction and probability of neonatal outcome in isolated congenital diaphragmatic hernia using multiple ultrasound parameters. Ultrasound in Obstetrics \& Gynecology 2012; 39(1): 42-9.

65. Cannie M, Jani J, Chaffiotte C, et al. Quantification of intrathoracic liver herniation by magnetic resonance imaging and prediction of postnatal survival in fetuses with congenital diaphragmatic hernia. Ultrasound Obstet Gynecol 2008; 32(5): 627-32.

66. Jani JC, Peralta CFA, Nicolaides KH. Lung-to-head ratio: a need to unify the technique. Ultrasound in Obstetrics \& Gynecology 2012; 39(1): 2-6.

67. Jani J, Nicolaides KH, Keller RL, et al. Observed to expected lung area to head circumference ratio in the prediction of survival in fetuses with isolated diaphragmatic hernia. Ultrasound Obstet Gynecol 2007; 30(1): 67-71.

68. Marden PM, Smith DW, McDonald MJ. Congenital anomalies in the newborn infant, including minor variations. A study of 4,412 babies by surface examination for anomalies and buccal smear for sex chromatin. J Pediatr 1964; 64: 357-71.

69. Brasil. Ministério da saúde. Secretaria de atenção à saúde ( manual). Pré natal e Puerpério: atenção qualificada e humanizada. Brasília. 2006.

70. Kaiser L, Arany A, Veszprémi B, Vizer M. [Hydrops fetalis--a retrospective study]. Orv Hetil 2007; 148(10): 457-63.

71. Phelan JP, Smith CV, Broussard P, Small M. Amniotic fluid volume assessment with the four-quadrant technique at 36-42 weeks' gestation. J Reprod Med 1987; 32(7): $540-2$.

72. Hadlock FP, Harrist RB, Sharman RS, Deter RL, Park SK. Estimation of fetal weight with the use of head, body, and femur measurements - A prospective-study. American Journal of Obstetrics and Gynecology 1985; 151(3): 333-7.

73. Battagli.Fc, Lubchenc.Lo. A practical classification of newborn infants by weight and gestational age. Journal of Pediatrics 1967; 71(2): 159-\&.

74. Zugaib M, Liao AW, Brizot ML, Carvalho MHB, Bunduki V. Medicina Fetal. $3^{\text {a }}$ ed. São Paulo; Editora Atheneu: 2012; p 635-636.

75. Zugaib M, Liao AW, Brizot ML, Carvalho MHB, Bunduki V. Medicina Fetal. $3^{\text {a }}$ ed. São Paulo; Editora Atheneu: 2012; p 642-643.

76. Zugaib M, Liao AW, Brizot ML, Carvalho MHB, Bunduki V. Medicina Fetal. $3^{\text {a }}$ ed. São Paulo; Editora Atheneu: 2012; p 161.

77. Mann S, Johnson MP, Wilson RD. Fetal thoracic and bladder shunts. Seminars in Fetal \& Neonatal Medicine 2010; 15(1): 28-33. 
78. Silveira MF, Santos IS, Matijasevich A, Malta DC, Duarte EC. [Preterm births in Brazil from 1994 to 2005 according to the Information System on Live Births (SINASC)]. Cad Saude Publica 2009; 25(6): 1267-75.

79. Usui N, Kitano Y, Okuyama H, et al. Prenatal risk stratification for isolated congenital diaphragmatic hernia: results of a Japanese multicenter study. Journal of Pediatric Surgery 2011; 46(10): 1873-80.

80. da Fonseca EB, Bittar RE, Carvalho MHB, Zugaib M. Prophylactic administration of progesterone by vaginal suppository to reduce the incidence of spontaneous preterm birth in women at increased risk: A randomized placebo-controlled double-blind study. American Journal of Obstetrics and Gynecology 2003; 188(2): 41924.

81. Meis PJ, Klebanoff M, Thom E, et al. Prevention of recurrent preterm delivery by 17 alpha-hydroxyprogesterone caproate. New England Journal of Medicine 2003; 348(24): 2379-85.

82. Mazaki-Tovi S, Romero R, Kusanovic JP, et al. Recurrent preterm birth. Seminars in Perinatology 2007; 31(3): 142-58.

83. Slattery MM, Morrison JJ. Preterm delivery. Lancet 2002; 360(9344): 1489-97.

84. Cederholm M, Haglund B, Axelsson O. Maternal complications following amniocentesis and chorionic villus sampling for prenatal karyotyping. Bjog-an International Journal of Obstetrics and Gynaecology 2003; 110(4): 392-9.

85. Liao C, Wei JX, Li QM, Li LX, Li J, Li DZ. Efficacy and safety of cordocentesis for prenatal diagnosis. International Journal of Gynecology \& Obstetrics 2006; 93(1): 13-7.

86. Gordon MC, Narula K, O'Shaughnessy R, Barth WH. Complications of thirdtrimester amniocentesis using continuous ultrasound guidance. Obstetrics and Gynecology 2002; 99(2): 255-9. 